\title{
COLOMBIA. DEMOCRACIA DE BAJA CALIDAD E INEQUIDADES SOCIALES. ${ }^{1}$ COLOMBIA. LOW-QUALITY DEMOCRACY AND SOCIAL INEQUALITIES.
}

Javier Duque Daza*

RESUMEN: El artículo analiza la relación entre la calidad de la democracia y la desigualdad social en Colombia. El argumento central es que Colombia tiene una democracia de baja calidad que se expresa en las dimensiones procedimentales y también en otras de índole sustancia o sustantivo. Colombia es una de las democracias de más baja calidad en América Latina y en la dimensión de igualdad es uno de los países de peores condiciones de vida de sus ciudadanos. Las personas reciben muy poco de la democracia, de las políticas públicas y de las decisiones de quienes representan o expresan los intereses generales de la sociedad. El articulo hace parte de una investigación mayor comparada coordinada por Leonardo Morlino.

Palabras-clave: democracia; calidad de la democracia; desigualdad; derechos sociales; pobreza.

\footnotetext{
${ }^{1}$ Esta publicación hace parte de un trabajo sobre la calidad de la democracia apoyado mediante la beca de estancia de investigación de la Universidad Nacional Autónoma de México y la Dirección General de Asuntos de Personal Académico, DGAPA.

* Doctor en Ciencia Política; Profesor en la Universidad del Valle (Univalle), Cali, Valle del Cauca, Colombia; E-mail: jduqued86@hotmail.com
} 
ABSTRACT: This paper analyses the relationship between the quality of democracy and social inequality in Colombia. The central argument is that Colombia has a low-quality democracy expressed in the procedural and also in other dimensions of substance or substantive nature. Colombia is one of the lowest quality democracies in Latin America and in the dimension of equality is one of the countries worst living conditions of its citizens. People get very little of democracy, public policies and decisions of those who represent or express the general interests of society. The article is part of a larger comparative research coordinated by Leonardo Morlino.

Keywords: democracy; quality of democracy; inequality; social rights; poverty.

\section{INTRODUCCIÓN}

En la última década el estudio de la democracia en América Latina presentó un giro importante, los análisis sobre las condiciones de las transiciones de regímenes autoritarios a democráticos, los referidos a la consolidación y a la estabilidad de la democracia, fueron desplazados parcialmente por estudios centrados en el desarrollo, las características y la calidad de la democracia. Un número creciente de análisis se focalizan en los atributos de las democracias y a la multiplicidad de adjetivos se agregó el eje analítico de la calidad, con ello surgieron conceptualizaciones, perspectivas explicativas, propuestas metodológicas y de medición.

Aunque abundan los estudios sobre la democracia en América latina que focalizan el análisis en sus dimensiones procedimentales o funcionales de índole político, señalando casi siempre las deficiencias, limitaciones y defectos, por contraste, escasean los trabajos sobre los efectos que generaba la democracia política en la igualdad social, en la redistribución de la riqueza. Los énfasis han recaído en la democracia como forma de gobierno, esto es, en la igualdad en el ejercicio de los derechos políticos como votar, ser elegido, formar y/o pertenecer a alguna organización o partido político, expresarse libremente, la com- 
petencia política, la regularidad en las elecciones. La democracia se asociaba a su contenido o concepción minimalista, de la competencia por el poder político con ciudadanos con plenitud de derechos políticos. Los derechos sociales han sido considerados otro asunto y no suelen ser incluidos ni en el concepto ni en el análisis.

Durante los últimos tres lustros, nuevas perspectivas analíticas sobre la calidad de la democracia superan el tradicional dilema de la separación entre igualdad política e igualdad económico-social. No se analiza a la democracia solo en su funcionalidad política y en sus procedimientos y la consagración de derechos políticos, también se ha incluido en la agenda de investigación cuestiones sustanciales relacionadas con sus efectos, su contenido o, si se prefiere, con sus dimensiones sustanciales. La cuestión no es solo cómo funciona la democracia, sino también para qué la democracia y cómo se traduce en las condiciones de vida de la población.

En la literatura sobre la calidad de la democracia algunos estudios mantienen el análisis en términos de los componentes básicos de la poliarquía (Corbetta y Pérez Liñan, 2001; Mainwaring y Pérez Liñán, 2008), en las dimensiones propias del régimen político, en los procesos y procedimientos y el componente central de la realización de la libertad. Otros van más allá y consideran también dimensiones referidas al control de parte de la sociedad del poder político, en términos de rendición de cuentas, la vigencia del Estado de Derecho y los resultados o productos de la democracia en términos de igualdad y libertad (Diamond y Morlino, 2004; Morlino, 2009 y 2013; Hagopian, 2005; Levine y Molina, 2007; Barreda, 2010). De forma más amplia, el concepto de calidad de la democracia se ha complejizado y la propuesta de mayores alcances ha incluido dimensiones procedimentales y sustanciales, como lo propone Leonardo Morlino quien adopta un concepto de calidad de la democracia integral, entendido como "la ordenación institucional estable que a través de instituciones y mecanismos que funcionan correctamente, realiza la libertad y la igualdad de los ciudadanos. Una buena democracia es, antes que todo, un régimen ampliamente legitimado y, por lo tanto, estable, del cual los ciudadanos están plenamente satisfechos" (Morlino, 2009). La definición, 
en consonancia con la propuesta metodológica, incluye dimensiones procedimentales adoptadas del concepto ampliado de poliarquía de Robert Dahl (1971 y 1992) y otras dimensiones sustanciales que retoman tradiciones no minimalistas de la democracia y que van más allá del régimen político y asume sus efectos en la sociedad, en la libertad, la igualdad y las formas como produce aceptación social.

Morlino asigna al concepto de calidad tres connotaciones que se conjugan en un concepto general: como contenido (sus ciudadanos y la o las asociaciones y comunidades que forman parte gozan en medida superior a los mínimos de libertad e igualdad; como resultado (una buena democracia es, antes que todo, un régimen ampliamente legitimado y estable, del cual los ciudadanos están plenamente satisfechos) y como procedimiento (por las características que les son propias, los ciudadanos de una buena democracia deben poder controlar y evaluar si y cómo esos dos valores se realizan a través del pleno respeto de las normas vigentes, el llamado rule of law, su eficiente aplicación, la eficacia en la toma de las decisiones junto a la responsabilidad política por las elecciones tomadas por el personal elegido también en relación a las preguntas expresadas por la sociedad civil. Estas tres dimensiones son descritas en el presente análisis sobre Colombia como el producto del análisis de caso derivado del análisis general sobre la calidad de la democracia en América Latina adelantada por Morlino, pero el énfasis recae en las dos primeras dimensiones: el contenido de la democracia en términos de igualdad social y en términos de resultado, del grado de legitimidad que tiene ante los ciudadanos.

El artículo adopta para el análisis la propuesta metodológica elaborada por Leonardo Morlino para el estudio comparado de la calidad de la democracia en América Latina. Este análisis propone dos dimensiones (procedimental y sustancial) y ocho subdimensiones y sus respectivos indicadores (imperio de la ley; accountability electoral, accountability interinstitucional, participación política, competencia política, responsabilidad, libertad e igualdad, ver tabla 1). 
Tabla 1 - Dimensiones y subdimensiones de la calidad de la democracia en Colombia

\begin{tabular}{|c|c|c|c|}
\hline & 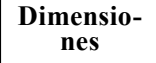 & Subdimensiones & Indicadores \\
\hline \multirow{5}{*}{ 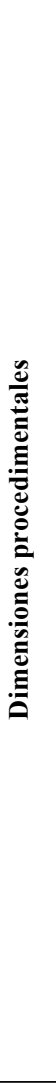 } & $\begin{array}{l}\text { Imperio de } \\
\text { la ley }\end{array}$ & $\begin{array}{l}\text {-Seguridad y orden civil } \\
\text {-Independencia judicial y } \\
\text { aparato de justicia } \\
\text {-Capacidad de las institu- } \\
\text { ciones } \\
\text {-Lucha contra la corrupción } \\
\text {-Fuerzas bajo control civil }\end{array}$ & $\begin{array}{l}\text {-Homicidios/delincuencia/ } \\
\text {-Autonomía justicia/Niveles im- } \\
\text { punidad/ } \\
\text {-Niveles corrupción/ } \\
\text {-Presencia organizaciones ar- } \\
\text { madas ilegales }\end{array}$ \\
\hline & $\begin{array}{l}\text { Accoun- } \\
\text { tability } \\
\text { electoral }\end{array}$ & $\begin{array}{l}\text {-Elecciones e integridad } \\
\text { electoral } \\
\text {-Libertad para organizar } \\
\text { partidos } \\
\text {-Presencia y estabilidad de } \\
\text { alternativas políticas } \\
\text {-Instituciones electorales }\end{array}$ & $\begin{array}{l}\text {-Fraude electoral/coacción sobre } \\
\text { los electores/ } \\
\text { Manipulación electoral/ } \\
\text {-Garantías políticas// } \\
\text {-Alternancia/Volatilidad electo- } \\
\text { ral/Nivel de continuidad de par- } \\
\text { tidos políticos } \\
\text {-Autonomía/Confianza ciuda- } \\
\text { dana }\end{array}$ \\
\hline & $\begin{array}{l}\text { Accoun- } \\
\text { tability } \\
\text { interinstitu- } \\
\text { cional }\end{array}$ & $\begin{array}{l}\text {-Relaciones poderes Ejecu- } \\
\text { tivo y Legislativo } \\
\text {-Corte Constitucional } \\
\text {-Información plural e inde- } \\
\text { pendiente } \\
\text {-Defensor del pueblo } \\
\text {-Descentralización }\end{array}$ & $\begin{array}{l}\text {-Autonomía parlamento/ } \\
\text {-Existencia/Autonomía } \\
\text {-Pluralidad medios de informa- } \\
\text { ción/ } \\
\text {-Existe/Funciones/ } \\
\text {-Elección autoridades locales/ } \\
\text { descentralización fiscal y admi- } \\
\text { nistrativa. }\end{array}$ \\
\hline & $\begin{array}{l}\text { Participa- } \\
\text { ción política }\end{array}$ & $\begin{array}{l}\text {-Oportunidades para la } \\
\text { participación } \\
\text {-Elecciones y referendo } \\
\text {-Partidos y asociaciones } \\
\text {-Participación no conven- } \\
\text { cional } \\
\text {-Democracia deliberativa }\end{array}$ & $\begin{array}{l}\text {-Mecanismos de participación } \\
\text { ciudadana } \\
\text {-Niveles abstención/referendo/ } \\
\text { Plebiscitos } \\
\text {-Nivel de asociacionismo/de- } \\
\text { mocracia interna en los partidos } \\
\text { políticos/ } \\
\text {-Activismo y acción colectiva/ } \\
\text { Tasas de sindicalización } \\
\text {-Espacios y procedimientos de } \\
\text { deliberación. }\end{array}$ \\
\hline & $\begin{array}{l}\text { Competen- } \\
\text { cia política }\end{array}$ & $\begin{array}{l}\text {-Competencia entre actores } \\
\text { políticos y sociales } \\
\text {-Competencia dentro de los } \\
\text { partidos } \\
\text {-Alternancia. }\end{array}$ & $\begin{array}{l}\text {-Nivel competitividad de las } \\
\text { elecciones } \\
\text {-Selección de candidatos parti- } \\
\text { distas } \\
\text {-Rotación y alternancia en el } \\
\text { poder }\end{array}$ \\
\hline \multirow{3}{*}{ 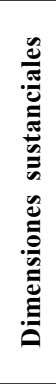 } & $\begin{array}{l}\text { Responsa- } \\
\text { bilidad }\end{array}$ & $\begin{array}{l}\text {-Legitimidad percibida } \\
\text {-Limitaciones a la demo- } \\
\text { cracia }\end{array}$ & $\begin{array}{l}\text {-Niveles de aceptación de políti- } \\
\text { cas/niveles de aceptación de las } \\
\text { instituciones } \\
\text {-Niveles de aceptación de la de- } \\
\text { mocracia. } \\
\end{array}$ \\
\hline & Libertad & $\begin{array}{l}\text {-Derechos civiles } \\
\text {-Derechos políticos }\end{array}$ & $\begin{array}{l}\text {-Niveles de derechos civiles } \\
\text {-Niveles de derechos políticos }\end{array}$ \\
\hline & Igualdad & $\begin{array}{l}\text {-Asignación de recursos } \\
\text {-Existencia de discrimi- } \\
\text { nación } \\
\text {-Derechos sociales y eco- } \\
\text { nómicos }\end{array}$ & $\begin{array}{l}\text {-Niveles de inversión social/nive- } \\
\text { les de pobreza e indigencia/Gini } \\
\text {-Ley de cuotas/Acceso a mino- } \\
\text { rías políticas/ } \\
\text {-Derecho y acceso a la educa- } \\
\text { ción/Derecho y acceso a la salud/ }\end{array}$ \\
\hline
\end{tabular}

Fuente: elaboración propia con base en la metodología propuesta en el proyecto la Calidad de la democracia en América latina, Red de Investigadores de la calidad de la democracia. Coordinador Leonardo Morlino. 
El análisis está centrado en la dimensión sustancial de la igualdad y el argumento central es que Colombia no solo se ubica entre las democracias de más baja calidad en América latina, sino que, además, en la dimensión de igualdad, se ubica entre los países de peores condiciones de vida de sus ciudadanos. Las personas reciben muy poco de la democracia, de las políticas públicas y de las decisiones de quienes representan o expresan los intereses generales de la sociedad. En esta condición de baja calidad de la democracia y desigualdad social inciden dos factores centrales: las características de fragilidad estatal y la naturaleza y características de la dirigencia política y de los partidos políticos que adelantan formas de gestión pública generadoras de desigualdades sociales, con base en formas de intermediación clientelar, patrimonialista y basadas en acceso desigual y particularista a los bienes y servicios.

El artículo se divide en tres partes. La primera caracteriza a Colombia como una democracia de baja calidad y la ubica en el contexto latinoamericano, la segunda parte presenta los principales indicadores sociales y de exclusión en las dos últimas décadas y la tercera parte adelanta el análisis sobre las políticas, la gestión pública y su incidencia directa en la baja calidad democrática en el país.

\section{DEMOCRACIA DE BAJA CALIDAD}

Como se observa en la tabla 2, en los resultados generales de la democracia en América Latina propuesto por Morlino (2012) se pueden diferenciar al menos tres subgrupos de países según sus niveles de calidad de la democracia: el primero corresponde a los casos de democracias de mayor calidad en la región, Chile, Uruguay, Costa Rica y Brasil, que en una escala de 0-5 se ubican entre 3.51-4.0; el segundo a países de calidad media, entre 3.0 y 3.50 (Perú, México, Ecuador y Argentina) y el tercero de baja calidad, con puntajes inferiores a 3.0 (Bolivia, Paraguay, Colombia, Nicaragua, El Salvador, Guatemala, Nicaragua y Venezuela).

Estos resultados no difieren mucho de estudios similares, aunque tienen dimensiones y formas de medir diferentes. Por ejem- 
plo Daniel Levine y José Enrique Molina (2007) consideran a los países con mayor calidad de la democracia a Chile, Costa Rica, Uruguay, Panamá y Argentina; a países intermedios a México, Brasil, El Salvador, Nicaragua, Honduras, Bolivia y los países de más baja calidad son Paraguay, Colombia, Venezuela, Guatemala. Aunque hay diferencias y el análisis incluye información hasta mediados de la década del 2000, coinciden en los países de más baja calidad democrática. ${ }^{1}$ Asimismo, Mikel Barreda (2010) al comparar diversos estudios encuentra similitudes, en términos generales, en la ubicación de los países y distingue tres grandes grupos. Chile, Uruguay, Costa Rica y Panamá son los países con un nivel de calidad democrática más elevado, especialmente los tres primeros. Por el contrario, Guatemala, Paraguay, Venezuela, Colombia, Honduras y Ecuador conforman el grupo con un nivel más bajo de calidad democrática, con particular énfasis en los cuatro primeros casos. Finalmente, los ocho países restantes se hallan en una posición intermedia. De ellos, Brasil y República Dominicana se sitúan en las posiciones más favorables, mientras que Bolivia y El Salvador en las menos favorables.

Tabla 2 - Calidad de la democracia en América Latina

\begin{tabular}{|c|c|c|c|c|c|c|c|c|c|}
\hline & ED & AE & AII & PP & CP & L & I & R & $\begin{array}{c}\text { Pro- } \\
\text { medio }\end{array}$ \\
\hline 1.Chile & 3.85 & 4.62 & 3.66 & 3.48 & 4.00 & 4.00 & 3.33 & 3.25 & 3.77 \\
\hline 2. Uruguay & 3.20 & 4.60 & 3.00 & 3.40 & 3.70 & 4.10 & 3.70 & 3.80 & 3.70 \\
\hline 3. Costa Rica & 3.72 & 4.08 & 3.52 & 3.13 & 3.56 & 4.10 & 3.42 & 3.38 & 3.61 \\
\hline 4. Brasil & 2.83 & 4.23 & 3.90 & 3.43 & 4.47 & 3.50 & 2.50 & 3.88 & 3.59 \\
\hline 5. Perú & 3.00 & 3.90 & 3.60 & 3.30 & 3.60 & 4.00 & 2.30 & 2.80 & 3.31 \\
\hline 6. México & 2.78 & 3.78 & 3.90 & 2.90 & 3.38 & 2.26 & 3.12 & 2.26 & 3.22 \\
\hline 7. Ecuador & 2.47 & 3.91 & 3.23 & 3.44 & 3.40 & 2.83 & 2.93 & 3.10 & 3.16 \\
\hline 8. Argentina & 2.80 & 3.25 & 3.40 & 3.60 & 2.50 & 3.80 & 2.67 & 2.50 & 3.09 \\
\hline 9. Bolivia & 2.12 & 3.30 & 2.82 & 3.88 & 2.60 & 3.11 & 2.33 & 2.30 & 2.81 \\
\hline 10. Paraguay & 2.42 & 3.53 & 2.95 & 2.83 & 2.75 & 3.13 & 2.55 & 2.25 & 2.80 \\
\hline 11. Colombia & 2.19 & 2.50 & 3.10 & 3.23 & 2.14 & 2.90 & 2.28 & 2.95 & 2.66 \\
\hline 12. Nicaragua & 1.97 & 3.41 & 2.68 & 2.96 & 3.17 & 2.08 & 2.00 & 2.50 & 2.60 \\
\hline
\end{tabular}

\footnotetext{
${ }^{1}$ Las dimensiones incluidas en este análisis son 1) decisión electoral; 2) participación; 3) respuesta a la voluntad popular; 4) responsabilidad; y 5) soberanía. El índice que proponen va de o a 100 y establecen un ranking para 18 países a cuya cabeza están Uruguay (93.7), Chile (92.3), Costa Rica (92.1) y Panamá (86.2). Luego siguen Argentina (82.9), México (82.5), República Dominicana (82.1), Brasil (76.4), Perú (75.4), El Salvador (74.4). Luego siguen los países con menores valores: Bolivia (70.3), Nicaragua (70.0), Paraguay (69.8), Honduras (69.3), Ecuador (68.9), Venezuela (67.8), Colombia (56.9) y Guatemala (56.5).
} 


\begin{tabular}{|c|c|c|c|c|c|c|c|c|c|}
\hline & ED & $\mathbf{A E}$ & AII & PP & CP & $\mathbf{L}$ & I & $\mathbf{R}$ & $\begin{array}{l}\text { Pro- } \\
\text { medio }\end{array}$ \\
\hline 13. El Salvador & 2.09 & 3.70 & 2.64 & 2.11 & 2.50 & 2.17 & 2.17 & 2.88 & 2.53 \\
\hline 14. Guatemala & 1.88 & 3.57 & 2.51 & 2.34 & 3.17 & 2.08 & 1.42 & 2.63 & 2.45 \\
\hline 15. Venezuela & 1.16 & 2.40 & 1.40 & 3.70 & 3.00 & 2.07 & 2.67 & 2.50 & 2.36 \\
\hline $\begin{array}{c}\text { Promedio } \\
\text { Dimensiones }\end{array}$ & 2.57 & 3.65 & 3.06 & 3.18 & 3.17 & 3.17 & 2.63 & 2.93 & 3.04 \\
\hline \multicolumn{10}{|c|}{$\begin{array}{c}\text { Fuente: Proyecto Calidad de la democracia en América Latina. } \\
\text { Coordinador Leonardo Morlino. } 2014\end{array}$} \\
\hline \multicolumn{5}{|c|}{$\begin{array}{c}\text { ED: Estado de derecho } \\
\text { AE: Accountability electoral } \\
\text { AII: Accountability interinstitucional } \\
\text { PP: Participación política }\end{array}$} & \multicolumn{5}{|c|}{$\begin{array}{c}\text { CP: Competencia políti } \\
\text { L : Libertad } \\
\text { I : Igualdad } \\
\text { R : Responsividad }\end{array}$} \\
\hline
\end{tabular}

Con dimensiones, subdimensiones e indicadores en ocasiones diferentes y con mediciones que difieren en algunos aspectos, hay cierto acuerdo en la ubicación general de los países, y dentro de todos los análisis de la calidad de la democracia Colombia es ubicada como un caso de baja calidad democrática. De las ocho dimensiones que incluye el marco de análisis del presente estudio sobre América Latina Colombia sólo supera el umbral mínimo de 3.0 en dos de las dimensiones y en promedio se ubica entre las democracias de más baja calidad y ocupa el lugar número 11 entre 15 países analizados.

Invirtiendo los términos de la definición propuesta por Morlino, una democracia de baja calidad conlleva a que la estructura institucional no hace posible ni propicia condiciones para la libertad y la igualdad de los ciudadanos y el funcionamiento de sus mecanismos y las dimensiones procedimentales tampoco es el adecuado respecto a los componentes básicos de la funcionalidad democrática, ni el régimen es ampliamente legitimidad por el consentimiento o aceptación de la sociedad. En este caso, como se observa en la tabla 3, de las cinco dimensiones de procedimiento (Estado de derecho, accountability electoral, accountability interinstitucional, participación política y competencia política), solo dos presentan valores superiores a 3.0 en una escala de $0-5.0$; la capacidad de respuesta presenta también déficits (expresada en términos de percepciones sobre la medida en que el sistema se corresponde con los deseos de los ciudadanos y de la sociedad civil en genera), así como las dimensiones relacionadas con el contenido de la democracia: la libertad y 
la igualdad (el respeto pleno a los derechos, que se expande mediante la conquista de una serie de libertades básicas y la aplicación progresiva de una mayor igualdad política, social y económica).

Tabla 3 - Colombia - Dimensiones de la calidad de la democracia

\begin{tabular}{cc}
\hline Dimensión & Promedio \\
\hline Imperio de la ley & 2.19 \\
\hline Accountability electoral & 2.50 \\
\hline Accountability interinstitucional & 3.10 \\
\hline Participación política & 3.23 \\
\hline Competencia política & 2.14 \\
\hline Capacidad de respuesta & 2.95 \\
\hline Libertad & 2.90 \\
\hline Igualdad & 2.28 \\
\hline Promedio & 2.66 \\
\hline Puesto en América Latina & $11 / 15$ \\
\hline
\end{tabular}

La democracia colombiana se configura como una democracia de submínimos, en sus procedimientos, en sus dimensiones sustanciales de respeto a los derechos y libertades civiles y en sus resultados. Esta situación se deriva de dos factores centrales: de las deficiencias del Estado, de su incapacidad y debilidades estructurales y su captura parcial por parte de actores ilegales; y de la naturaleza de la clase política y de los partidos políticos. Colombia constituye un caso típico de democracia con estado débil y cooptado parcialmente por la criminalidad. Como lo subrayaba Guillermo O'Donnell (2007) refiriéndose a algunos casos de América Latina, se trata de una novedad en la historia política de occidente dado que las democracias que se consolidaron lo hicieron sobre la base de la estatalidad, de la capacidad del Estado para mantener niveles de coacción e institucionalidad básicos para mantener la regulación social.

El caso colombiano permite ilustrar la relación entre un Estado deficiente y capturado parcialmente por la criminalidad y una democracia deficitaria. En términos de Scott Mainwaring (2007) se trata de una sociedad con deficiencias estatales, en las cuales el Estado no cumple algunas de sus funciones básicas de gobierno, de justicia 
y de seguridad ${ }^{2}$. El Estado ejerce soberanía interna parcial pero con serias dificultades en el monopolio sobre los instrumentos de coacción física por cuanto el control del territorio le es disputado por grupos armados que se constituyen en actores que ejercen violencia contra la sociedad (grupos guerrilleros de extrema izquierda y paramilitares de extrema derecha). Asimismo, presenta dificultades en el manejo de la corrupción de sus funcionarios y fuerzas armadas, incapacidad para implementar las normas legales, para hacer cumplir la justicia y para ser eficiente en la provisión de bienes y servicios básicos.

Por otra parte, se trata de un Estado capturado o cooptado parcialmente por la criminalidad, que interfiere en los procesos legislativos, en la orientación de los recursos, en la política de seguridad y convivencia; en las decisiones de políticas públicas y en la financiación y manejo de los partidos políticos. No se ha garantizado el imperio de la ley, ni se ha concentrado el monopolio de la fuerza y de las finanzas públicas, entonces el Estado es un actor adicional que también participa en la disputa con grupos criminales con alta capacidad de incidencia en las decisiones, en los órganos de poder, en la fuerza pública, en los partidos políticos (Elías 1989; Hellman y Kaufmann, 2001). Algunos actores ilegales, en algunos aspectos incluso tanto o más fuertes que el mismo Estado en el nivel central o especialmente en los niveles territoriales y locales, están interesados en suplantarlo y dominarlo en instancias decisivas para lograr los intereses particulares. Algunos de estos actores son mafias, carteles ilegales, organizaciones criminales, grupos antisubversivos y grupos subversivos (Garay, 2008).

\footnotetext{
${ }^{2}$ El referente respecto al cual se asume la precariedad o inefectividad del Estado implica que este incluye algunos componentes básicos que, cuando se desempeñan bien, cumple su papel de articulador y ordenador de la diversidad y pluralidad de las relaciones sociales en su territorio: (1) conjunto de burocracias, organizaciones complejas y jerárquicamente pautadas, tienen legalmente asignadas responsabilidades apuntadas a lograr o proteger algún aspecto del bien o interés público general; (2) un sistema legal, un entramado de reglas que penetran y codeterminan numerosas relaciones sociales, que expresan también la capacidad de generar el gran bien público del orden general y de la previsibilidad de una amplia gama de relaciones sociales, (3) un foco de identidad colectiva para los habitantes de su territorio, (4) El Estado es un filtro que trata de regular las fronteras internas y externas del territorio (O’Donnell, 2004 y 2007). En el mismo sentido Rotberg (2007) señala que "las funciones primordiales son proporcionar el bien político de seguridad: prevenir las invasiones e infiltraciones transfronterizas y cualquier pérdida de territorio; eliminar las amenazas domésticas y los ataques al orden nacional y a la estructura social; prevenir el crimen y cualquier peligro relacionado con la seguridad doméstica humana; y permitir a los ciudadanos que resuelvan sus diferencias con el Estado y con sus conciudadanos sin el recurso a las armas o a otras formas de coerción física"(2007, p.158).
} 
Respecto a las ocho dimensiones y las variables explicativas se pueden sintetizar los siguientes enunciados: (1) existen severas limitaciones en el imperio de la ley. Aunque hay normas y un marco legal general, hay una gran distancia entre estas y la realidad, esto es, hay una débil institucionalización. Esta dimensión adquiere un papel central en el caso de Colombia y es la expresión del Estado inconcluso, en los términos de Guillermo O'Donnell (2005) se trata de la ausencia de soberanía interior y de precariedad estatal que generan, como es planteado en el marco de análisis, un efecto directo sobre la libertad (2); sobre la igualdad (3) y sobre la accountability interinstitucional (4). A su vez, el constreñimiento a las libertades y la existencia de desigualdad ante la ley y en las condiciones de vida por acceso a bienes y servicios, inciden en las otras cuatro dimensiones: en la competencia (5) y en la participación (6): las formas individuales y colectivas de participación son afectadas por la coacción y la violencia en algunas zonas del país, así como por las extendidas prácticas de clientelismo y redes de apoyo informales y transaccionales que afectan la autonomía del ciudadano. En cuanto a la accountability electoral (7): las elecciones no son libres sólo parcialmente, con recurrentes casos de "urnas contaminadas" por la manipulación de los resultados y hay una gran volatilidad e inestabilidad en la presencia de partidos políticos. En la responsabilidad y las respuestas que dan las autoridades y los gobernantes a las expectativas y necesidades de los ciudadanos (8): hay una percepción muy negativa de las instituciones representativas (partidos políticos, Congreso, clase política) y un importante segmento de la población manifiesta su desconfianza y dudas acerca de la democracia y del sistema político. Ello implica una evaluación muy negativa de quienes gobiernan y sobre los resultados de sus acciones (Duque, 2014).

$\mathrm{El}$ argumento anterior de las deficiencias estatales en sus tres dimensiones es complementado con otro que enfatiza en la incidencia de los partidos políticos en la baja calidad de la democracia en el país: la naturaleza clientelar de los partidos y el predominio de políticos de negocios, con su consecuente representación parcial y privatizada de intereses alteran su funcionalidad de intermediadores y representa- 
dores de interese generalizables e inciden en varias dimensiones de la calidad de la democracia: en la responsividad, en la accountability electoral, la competencia, la participación y la igualdad.

En otros trabajos se ha desarrollado en detalle este argumento (Duque, 2014). En este caso el interés está centrado en las dimensiones referidas a los productos de la calidad de la democracia, lo que reciben los ciudadanos del régimen político en términos de sus condiciones de vida y la forma como perciben, aceptan o rechazan este régimen político.

\section{BAJA CALIDAD DEMOCRÁTICA Y DESIGUALDAD SOCIAL}

Colombia presenta una puntuación muy baja en la dimensión igualdad (2.28). Esta dimensión indaga por los derechos sociales, económicos y culturales, las dimensiones clave también se refieren al esquema real de asignación de recursos económicos dentro de la población, a la difusión de la educación, el nivel de pobreza, la existencia de discriminación por razones de género y de discriminación étnica o racial. El tipo de preguntas que incluye la investigación comparada en que se basa este artículo son básicamente tres: 1) respecto a la asignación de recursos económicos, culturales y sociales: ¿Cuál es la concentración de recursos y el nivel de pobreza? 2) respecto a la existencia de discriminación: ¿Cuáles son las características y el alcance de la discriminación? 3) en cuanto a los derechos sociales, económicos y culturales: ¿Qué nivel de desarrollo y eficacia ha alcanzado el Estado de bienestar? (Morlino, 2013).

Respecto a la primera pregunta, Colombia es uno de los países con mayor desigualdad de la distribución de la riqueza de América Latina y del mundo. Según el Gini durante la década 2003-2013 Colombia se ubica en el cuarto peor lugar de América latina, sólo tienen peores condiciones Haití (el país más pobre de la tierra), Honduras y Bolivia. De acuerdo con el Índice Palma, ocupa el tercer lugar en desigualdad en el mismo periodo ${ }^{3}$. En el 2014 Colombia

${ }^{3}$ La relación de la participación del Ingreso Nacional Bruto (INB) del $10 \%$ más rico de la población dividida entre la participación del $40 \%$ más pobre. Se basa en la obra de Palma (2011), quien descubrió que los ingresos de la clase media casi siempre representan alrededor de la mitad del INB, mientras que la otra mitad se divide entre el $10 \%$ más rico y el $40 \%$ más pobre, pero la par- 
ocupó el puesto 12 entre 168 países, según el Informe de Desarrollo Humano de las Naciones Unidad.

Tabla 4 - Desigualdad social: posición de Colombia en América latina según Gini e índice Palma

\begin{tabular}{|c|c|c|}
\hline Países & $\begin{array}{c}\text { Índice Palma } \\
2003-2013\end{array}$ & $\underset{2003-2013}{\text { Gini }}$ \\
\hline Haití & --- & 0.592 \\
\hline Honduras & 5.2 & 0.570 \\
\hline Bolivia & 4.8 & 0.563 \\
\hline Colombia & 4.5 & 0.559 \\
\hline Guatemala & 4.5 & 0.559 \\
\hline Brasil & 4.3 & 0.547 \\
\hline Paraguay & 3.7 & 0.524 \\
\hline $\begin{array}{l}\text { Chile } \\
\end{array}$ & 3.5 & 0.521 \\
\hline Panamá & 3.6 & 0.519 \\
\hline Costa Rica & 3.3 & 0.507 \\
\hline Ecuador & 3.1 & 0.493 \\
\hline El Salvador & 3.0 & 0.483 \\
\hline Perú & 2.9 & 0.481 \\
\hline México & 2.7 & 0.472 \\
\hline Venezuela & 2.4 & 0.448 \\
\hline Uruguay & 2.5 & 0.453 \\
\hline Argentina & 2.4 & 0.445 \\
\hline Nicaragua & 1.9 & 0.405 \\
\hline \multicolumn{3}{|c|}{$\begin{array}{l}\text { Fuente: Índice de Desarrollo Humano ajustado por desigualdad. Disponible en } \\
\text { http://www.undp.org/content/dam/undp/library/corporate/HDR/ 2014HDR/ } \\
\text { HDR-2014-Spanish.pdf }\end{array}$} \\
\hline
\end{tabular}

En la tabla 5 se observan las dimensiones básicas de la desigualdad social en Colombia: durante las dos últimas décadas el índice Gini en promedio es del 0.563 (en donde 0 es igualdad total y 1 , desigualdad absoluta). Aunque en los extremos del periodo se presenta una leve disminución, Colombia sigue siendo un país con una amplia desigualdad (entre 1993 y el 2010, el 1\% de los más ricos del país concentraban en promedio el 19,2\% de los ingreso y se ha mantenido constante en los extremos del periodo, es decir, cerca de

ticipación de esos dos grupos varía considerablemente entre los países. Un Palma grande implica que el 10\% más rico (decil X) incrementa su diferencia con el $40 \%$ más pobre (deciles I, II, III y IV). Un Palma bajo implica un cierre de esta brecha. 
dos décadas)(Sabaíni y Rossignolo, 2015). Por su parte, el coeficiente de Gini de concentración de la tierra para el conjunto del país en el 2009 era de 0,84 que expresa un extremo de la alta concentración, con el agravante de que los grandes propietarios de latifundio o de tierras productivas no pagan impuestos (Bonilla y González, 2012). Asimismo, aunque han disminuido en la última década, la pobreza y la indigencia sigue siendo de las más altas del continente, siendo mayor en las áreas rurales y presentando diferencias importantes entre regiones, las de Atlántico y pacífico de mayoría de población afrodescendiente los índices de pobreza son mayores. Aunque hay debate sobre las cifras oficiales, aún en el mejor de los casos el 28.5 por ciento de pobres reportados por el departamento nacional de estadística (DANE) corresponde a cerca de 13.700 .000 personas y en condición de extrema pobreza o indigencia cerca de 4 millones.

En cuanto a la Población Económicamente Activa, más de dos terceras partes trabaja en la informalidad, en desempleo disfrazado o subempleo ambulante o en las calles de las ciudades o en actividades familiares que impide que accedan a la seguridad social básica. Existe una amplia segmentación del mercado laboral en el que 6 de cada 10 trabajadores no están incorporados a seguridad social, no cuentan con empleos e ingresos estables, viven el día a día, habitan zonas subnormales o en seria s falencias de coberturas de servicios públicos, no cotizan al sistema pensional, no tienen capacidad de ahorro, tienen serios obstáculos para ingreso a educación básica secundaria y educación superior. Aunque el desempleo en las cifras oficiales se ha ido reduciendo en los últimos años, los nuevos empleos son muy precarios, con bajos salarios, a través de flexibilización laboral de órdenes de prestaciones de servicios, contratos a términos definidos cortos, sin prestaciones sociales o bajo la modalidad de salario integral y con el pago de la seguridad social a cargo de los empleados. 
Tabla 5 - Indicadores básicos de igualdad, pobreza y empleo en Colombia

\begin{tabular}{|c|c|c|c|c|c|}
\hline Año & Gini & $\begin{array}{c}\text { Población } \\
\text { en pobreza }\end{array}$ & $\begin{array}{c}\text { Población en } \\
\text { indigencia }\end{array}$ & Desempleo & Informalidad \\
\hline 1995 & 0.569 & 49.5 & 15.5 & 8.8 & --- \\
\hline 1996 & 0.544 & 50.9 & 17.3 & 11.2 & 52.3 \\
\hline 1997 & 0.555 & 52.7 & 18.5 & 12.4 & --- \\
\hline 1998 & 0.563 & 55.3 & 20.8 & 15.3 & 54.7 \\
\hline 1999 & 0.556 & 57.5 & 25.4 & 19.4 & --- \\
\hline 2000 & 0.566 & 55.0 & 19.0 & 17.3 & 60.0 \\
\hline 2001 & 0.570 & 55.2 & 18.7 & 18.2 & 60.5 \\
\hline 2002 & 0.590 & 57.0 & 20.7 & 17.6 & 61.3 \\
\hline 2003 & 0.560 & 50.7 & 15.8 & 16.7 & 60.7 \\
\hline 2004 & 0.576 & 52.7 & 17.4 & 15.4 & 58.7 \\
\hline 2005 & 0.576 & 49.2 & 14.7 & 13.9 & 58.8 \\
\hline 2006 & 0.586 & 50.3 & 15.7 & 23.0 & -- \\
\hline 2007 & 0.587 & 46.0 & 17.8 & 11.4 & -- \\
\hline 2008 & 0.562 & 42.7 & 16.5 & 11.5 & 55.6 \\
\hline 2009 & 0.593 & 40.4 & 14.5 & 13.0 & 63.9 \\
\hline 2010 & 0.557 & 33.2 & 12.3 & 12.4 & 63.0 \\
\hline 2011 & 0.545 & 30.5 & 10.6 & 11.5 & 51.3 \\
\hline 2012 & 0.536 & 32.9 & 10.4 & 11.2 & 62.7 \\
\hline 2013 & 0.536 & 30.7 & 9.1 & 10.6 & 61.2 \\
\hline 2014 & 0.538 & 28.5 & 8.1 & 10.1 & \\
\hline
\end{tabular}

Fuente: Para el Gini: Sarmiento Anzola, Libardo. Exclusión y Desarrollo Societal, hasta el año 2000; Informe de Desarrollo Humano PNUD 2001-2009 y http://www. dane.gov.co/files/investigaciones/condiciones vida/pobreza/cp pobreza 2011.pdf. Sobre desempleo 1995-2014: Cepal: http://interwp.cepal.org/sisgen/ConsultaIntegrada. asp? idIndicador $=127 \&$ idioma $=\mathrm{e}$

Informalidad y precarización del empleo: los efectos de la globalización, en: Economía y Desarrollo Vol 5 No 1, Bogotá. Para los años 2007-2008 www.presidencia.gov. co/sp/2009/febrero/06/medidas.pdf

Informalidad 2009-2013 http://www.ilo.org/wcmsp5/groups/public/---americas/--ro-lima/documents/publication/wcms_245615.pdf

Sobre pobreza: Misión para el diseño de una estrategia para la reducción de la pobreza y la desigualdad, 2006, Bogotá; hasta el 2008 Departamento Nacional de Planeación, Colombia http://www.dane.gov.co/files/investigaciones/condiciones_vida/ pobreza/cp_pobreza y Cepal, 2008-2014: http://interwp.cepal.org/sisgen/ConsultaIntegrada.asp?idIndicador $=250 \&$ idioma $=\mathrm{e}$

Por su parte, en términos del Índice de Desarrollo Humano de las Naciones Unidas (IDH) Colombia es ubicado en la última década en el grupo de países con alto desarrollo humano (en el 2013 fue del 0.711), pero teniendo en cuenta el ajuste por desigualdad se reduce drásticamente a un promedio de $0.478{ }^{4} \mathrm{y}$ en el último lustro se presentan grandes variaciones entre las ciudades y el campo y entre Bogotá y los departamentos de la región andina y el resto del país.

\footnotetext{
${ }^{4}$ PNUD Índice de Desarrollo Humano, 2024. Anexo estadístico http://hdr.undp.org/en/media/ HDR_2011_ES_Tables.pdf. El IDH tiene en cuenta la esperanza de vida al nacer, los años promedio de escolaridad, años esperados de escolarización, Índice de educación y el Ingreso Percapita.
} 
Tabla 6 - Índice de Desarrollo Humano

\begin{tabular}{|c|c|c|c|c|c|}
\hline Países & 2010 & 2011 & 2012 & 2013 & 2014 \\
\hline 1 Uruguay & 0.642 & 0.654 & 0.573 & 0.662 & 0.632 \\
\hline 2.Chile & 0.634 & 0.652 & 0.516 & 0.661 & 0.615 \\
\hline 3. Argentina & 0.622 & 0.641 & 0.560 & 0.600 & 0.605 \\
\hline 4. México & 0.593 & 0.589 & 0.500 & 0.583 & 0.566 \\
\hline 5. Costa Rica & 0.576 & 0.591 & 0.483 & 0.611 & 0.565 \\
\hline 6. Venezuela & 0.549 & 0.540 & 0.556 & 0.613 & 0.564 \\
\hline 7. Perú & 0.501 & 0.557 & 0.495 & 0.562 & 0.528 \\
\hline 8. Ecuador & 0.554 & 0.535 & 0.472 & 0.549 & 0.527 \\
\hline 9. Brasil & 0.509 & 0.519 & 0.452 & 0.542 & 0.505 \\
\hline 10. Paraguay & 0.482 & 0.505 & 0.428 & 0.513 & 0.482 \\
\hline 11. Colombia & 0.492 & 0.479 & 0.420 & 0.521 & 0.478 \\
\hline 12. El Salvador & 0.477 & 0.495 & 0.427 & 0.485 & 0.471 \\
\hline 13. Nicaragua & 0.426 & 0.427 & 0.391 & 0.452 & 0.428 \\
\hline 14. Bolivia & 0.398 & 0.437 & 0.388 & 0.470 & 0.423 \\
\hline 15. Guatemala & 0.372 & 0.393 & 0.367 & 0.422 & 0.388 \\
\hline Infrer & &
\end{tabular}

Informe de Desarrollo Humano (2014) Sostener el progreso humano: reducir vulnerabilidades y construir resiliencia, PMUD.

http://www.undp.org/content/dam/undp/library/corporate/HDR/2014HDR/ HDR-2014-Spanish.pdf

En cuanto a la segunda pregunta, en Colombia hay diversas expresiones de discriminación y trato desigual a importantes sectores de la población. Las características y alcances de la discriminación, en Colombia hay claros rasgos de segmentación, diferenciación y segregación. Por una parte, existen desigualdades y discriminación de género. En la medición de desigualdad de género del PNUD Colombia se ubica en el grupo de países con peores condiciones (0.482) que se concreta en el acceso diferenciado a cargos de representación y en los salarios. Aunque en algunos ámbitos se ha ido corrigiendo esta situación como en el acceso a la educación en todos los niveles, incluso en educación superior hay más mujeres que hombres, y se ha establecido una ley de $\operatorname{cuotas}^{5}$, aún persisten diferencias como en los ingresos sa-

\footnotetext{
${ }^{5}$ La Ley 581 de 2000 Mínimo el treinta por ciento (30\%) de los cargos del Máximo Nivel Decisorio serán desempeñados por mujeres; es decir los cargos de mayor jerarquía en las entidades de las tres Ramas y Órganos del Poder Público, en los niveles nacional, departamental, regional, provincial, distrital y municipal, así por ejemplo: en el orden nacional, en un Ministerio hacen parte de este nivel, el Ministro, Viceministro y Secretario General. En el territorial, los Secretarios de Despacho, se exceptúa el Alcalde por ser de elección popular. Mínimo el treinta por ciento (30\%) de los cargos de Otro Nivel Decisorio serán desempeñados por mujeres, es decir cargos de libre nombramiento y remoción, de la Rama Ejecutiva, del personal administrativo de la Rama Legislativa y de los demás Órganos del Poder Público, en los niveles nacional, departamental, regional, provincial, distrital y municipal, incluidos los cargos de libre nombramiento y remoción de la Rama Judicial.
} 
lariales (según un reciente análisis las mujeres reciben en promedio el 24 por ciento menos de salario que los hombres), además las mujeres realiza entre dos y cinco veces más asuntos de cuidado y trabajo doméstico no remunerado que los hombres. Por tanto, se limitan sus oportunidades educativas, laborales y le queda menos tiempo para el descanso, el ocio o la participación política Según el informe de la Organización de Mujeres 2014, la tasa de desempleo de las mujeres es el doble que la de los hombres. Las mujeres tienen cada vez más años de escolaridad (promedio de 10 años frente a 9,2 los hombres) pero siguen teniendo dificultades para incorporarse al mercado laboral y cuando lo logran, lo hacen. El 51,6\% de las personas que viven en Colombia por debajo d La reforma electoral contenida en la Ley 1475 de 2011, aprobó que en las listas de candidatos para las elecciones a cuerpos colegiados se incluyeran al menos un 30\% de mujeres, lo cual representa un avance significativo en materia de acciones afirmativas de adecuación normativa para la igualdad de género; en la línea de pobreza son mujeres, lo que supone casi 8 millones de ciudadanas. De ellas, el 69,4\% vive en zona urbana y el 30,6\% en zonas rurales. En las cabeceras, los hombres presentan una tasa de pobreza de $29,8 \%$, y las mujeres de 30,9\%. En el resto, los hombres presentan una tasa de incidencia de 44,3\%, y las mujeres 48,1\%. , para el período 2010 - 2014, las mujeres en el Senado representan un $16 \%$ y en la Cámara de Representantes un $12 \%$. A nivel de gobernaciones, para el período 20122015, el 9,3\% de los gobiernos departamentales están en cabeza de una mujer (Quindío y San Andrés). Las diputadas en este nivel constituyen sólo el 17,9\% del total de representantes. Para el período 2008-2011, la participación de mujeres como alcaldesas fue del 9,9\%, sólo el $16 \%$ de mujeres son concejalas y un $9,3 \%$ gobernadoras. A pesar de que las mujeres en Colombia representan más de la mitad de la población colombiana en promedio sólo alcanzan un 12\% de los cargos de elección popular (Función Pública, 2014). ${ }^{6}$

Por otra parte, aunque la Constitución de 1991 incluyó aspectos importantes de ciudadanía diferenciada con medidas de discri-

\footnotetext{
${ }^{6}$ El Índice de Desigualdad de Género: Una medida compuesta que refleja la desigualdad en los logros entre hombres y mujeres en tres dimensiones: salud reproductiva, empoderamiento y mercado de trabajo.
} 
minación positiva para minorías indígenas y de afrodescendientes, persisten dinámicas socio-políticas y culturas discriminatorias étnicas en el país. ${ }^{7}$ La población negra en Colombia se calcula en el 12 por ciento (de un total de 48 millones), ubicada especialmente en los departamentos de la Costa pacífica o con subregiones en esta (Chocó, parte del Valle del Cauca, Cauca y Nariño), en la Costa Atlántica y en las ciudades como Cali, que concentra la mayor población afrodescendiente y aunque hay una abundante legislación orientada a garantizarles mejores condiciones de vida y derechos especiales, en la realidad considerando la población nacional en su conjunto, el porcentaje de afrocolombianos que está por debajo de la línea de pobreza es superior al de los "no étnicos" (53,7\% frente a 47,2\%) y que un porcentaje mayor de aquellos tiene necesidades básicas insatisfechas (NBI) (41,8\% frente a 29,9\%). El autor del documento citado observó además que dichas desigualdades son significativamente mayores en el Valle del Cauca, departamento que concentra la mayor cantidad de afrocolombianos en el país (allí un 50\% de los afrocolombianos están por debajo de la LP, mientras que el porcentaje es del 33,8 en el resto de la población; los porcentajes de población con NBI, por su parte, ascienden al 32,2\% y al 16,4\%, respectivamente). Buenaventura, el puerto más importante de Colombia en el Pacífico cuya población es en su mayoría afrodescendiente, tiene un índice de desempleo del $29 \%$ y un índice de subempleo del 35\%. El 80,6\% de sus habitantes vive en condiciones de pobreza y el $43,5 \%$, en condiciones de indigencia ((McDougall, 2010, PNUD, 2010). Es, además, una de las ciudades con mayores índices de violencia del país y en ella se entrecruzan las acciones de organizaciones criminales de diversa índole vinculadas todas con el narcotráfico.

Respecto a las minorías indígenas, que representan el 3.5 por ciento de la población agrupada en 87 grupos diferentes, fueron objeto de décadas de discriminación e invisibilidad en la vida pública. Con la Constitución de 1991 esta situación empezó a cambiar con las disposiciones de ciudadanía diferenciada que las beneficia, accedieron a escaños privilegiados y exclusivos en el Congreso y han

${ }_{7}^{7}$ Sobre mas minorías negras la legislación de derechos es abundante (Véase: PNUD, 2010). 
competido de forma exitosa en alcaldías, un gobernador (en el departamento de Cauca en el periodo 2002-2003), en concejos municipales y asambleas departamentales. Además de las disposiciones constitucionales ${ }^{8}$, se han creado instancias especializadas en las minorías indígenas como la defensoría delegada para los Indígenas y las Minorías Étnicas, adscrita a la defensoría del Pueblo; Ministerio de Gobierno, División de Asuntos Indígenas. Procuraduría Delegada para Asuntos Agrarios (encargada de asuntos indígenas y ambientales). No obstante los avances, persisten muchas situaciones que afectan de forma negativa los derechos de las minorías indígenas: son objeto de desplazamiento forzado por parte de grupos armados ilegales, paramilitares y grupos guerrilleros; son objeto de violencia política y en sus territorios se adelantan proyectos de explotación minera, narcotráfico y otras actividades económicas que han puesto en riesgo su sobrevivencia. La Corte Constitucional de Colombia, en el Auto 004 de 2009, había declarado que en términos generales, el conflicto armado y el desplazamiento forzado amenazan la existencia misma de numerosos pueblos indígenas colombianos, entre los cuales 34 fueron descritos como en situación de alto riesgo. A partir de esta declaración, la Organización nacional Indígena (ONIC) presentó en 2010 un diagnóstico en el que se consideraba que los factores causa-

\footnotetext{
${ }^{8}$ La Constitución Política incluye varios principios aplicables a las comunidades indígena: el artículo 1 define a la Nación Colombiana como un Estado social de derecho, descentralizado, democrático, participativo, pluralista, fundado en el respeto a la dignidad humana el trabajo, la solidaridad, y la prevalencia del interés general. El artículo 2 regula como fines esenciales del Estado servir a la comunidad, promover la prosperidad general, garantizar la efectividad de los principios constitucionales, derechos y deberes, facilitar la participación de todos en las decisiones que los afecten y en la vida económica, política administrativa y cultural de la Nación. El artículo 7 establece que el estado reconoce y protege la diversidad étnica y cultural de la Nación Colombiana. El artículo 58 garantiza el derecho a la propiedad privada, ordena que el interés privado debe ceder ante el interés general, le asigna a la propiedad una función ecológica, como parte de su función social. y le ordena la Estado proteger y promover las formas solidarias y asociativas de propiedad. El ordenamiento constitucional admite diversos modelos económicos gracias al reconocimiento de la diversidad cultural. Este es el caso de las economías de subsistencia de las comunidades indígenas que habitan el bosque húmedo tropical colombiano, en contrate con la economía capitalista. El artículo 63 determina que las tierras comunales de grupos étnicos, las tierras de resguardo, son inalienables, imprescriptibles e inenbargables. El derecho fundamental a la propiedad colectiva de los étnicos lleva implícito un derecho a la Constitución de resguardos en cabeza de las comunidades indígenas. El artículo 8 establece la obligación del Estado de proteger la riqueza cultural de la nación y el 9 el respeto de la autodeterminación de los pueblos. Por su parte, el artículo 79 determina que todas las personas tienen derecho a gozar de un ambiente sano y la ley garantizará la participación de la comunidad en las decisiones que puedan afectarlo. El artículo 330, sobre la explotación de recursos naturales, prevé que dicha explotación se hará sin desmedro de la integridad social, económica y cultural de las comunidades indígenas y además prevé la participación de los representantes de las comunidades en las decisiones que se adopten.
} 
les del riesgo de extinción física y cultural de los pueblos indígenas en Colombia eran los efectos devastadores del conflicto armado interno y sus múltiples consecuencias; la imposición de proyectos de desarrollo en territorios indígenas sin el debido consentimiento previo, libre e informado y el abandono estatal representado en pobreza, falta de acceso a servicios básicos y discriminación estructural (ONIC, 2010). Por otra parte, persisten acciones de discriminación social en su inserción laboral un reciente estudio determinó que los negros e indígenas una fuerte exclusión en las empresas del sector formal de la economía y la percepción de los jefes de personal sobre estas minorías es que son diferentes, el nivel educativo no es tan bueno, son menos cultos o muy distintas y en el nivel directivo de las empresas la exclusión es aún mayor (Urrea, 2014) y no acceden a los altos cargos del Estado. En los últimos años se ha ido legislando para remediar las actitudes y las acciones discriminatorias a través de la Ley Antidiscriminación y la Ley de Discapacidad. ${ }^{9}$

Respecto a la tercera cuestión sobre el nivel de desarrollo y eficacia que ha alcanzado el Estado de bienestar, hay un gran contraste entre los preceptos constitucionales y una abundante legislación sobre políticas sociales que formalmente apuntan a generar una ciudadanía social, pero que en su concreción y desarrollos tienen magros resultados. La Constitución de 1991 define a Colombia como un Estado Social de Derecho e incluye una extensa lista de derechos políticos, sociales, económicos y culturales (capítulos 1,2 y 3), pero, hay una gran brecha entre el formalismo jurídico y la realidad. Para mencionar solo tres sectores clave en el bienestar de las personas, en primer lugar, mientras que la Constituyen contempla igualdad de oportunidades para los trabajadores ${ }^{10}$, se impone, como lo expresan los datos ${ }^{9}$ Fue promulgada la ley 1482 de 2011 conocida como la Ley Antidiscriminación. En el 2014 se dio la primera condena por racismo en el país Un juez de Risaralda condenó al concejal del municipio de Marsella, Fernando Antonio Delgado, por el delito de hostigamiento por motivos de raza, religión, ideología, política, u origen nacional, étnico o cultural. El condenado fue llevado a juicio por la Fiscalía por unas declaraciones que entregó en el recinto del Concejo Municipal de esa ciudad, en medio de una sesión ordinaria el día 14 de agosto de 2012 en las que manifestó que "siendo sinceros, grupos difíciles de manejar como las negritudes, los desplazados y los indígenas, son un cáncer que tiene el Gobierno Nacional y mundial (El País, noviembre 28 de 2014).

${ }^{10} \mathrm{El}$ artículo 53 señala al respecto: "Igualdad de oportunidades para los trabajadores; remuneración mínima vital y móvil, proporcional a la cantidad y calidad de trabajo; estabilidad en el empleo; irrenunciabilidad a los beneficios mínimos establecidos en normas laborales; facultades para transigir y conciliar sobre derechos inciertos y discutibles; situación más favorable al trabajador en caso de duda en la aplicación e interpretación de las fuentes formales de derecho; primacía de la realidad 
de la tabla 5, la informalidad, la contratación flexible sin derechos de seguridad social, los contratos a término definido, el recorte en el pago de horas extras y recargos en festivos y nocturnos, el pago de cesantías y otras prestaciones sociales. El propio Estado ha tolerado la violación de la legislación laboral y las empresas tienden a generalizar la contratación a través de órdenes de prestación temporal de servicios en las que se desligan de sus responsabilidades laborales y trasfieren a los empleados el pago de su seguridad social. En segundo lugar, a la vez que se contempla como derecho la seguridad social ${ }^{11}$, el cubrimiento en el sector salud presenta muchas deficiencias en su cobertura y gran parte de los hospitales públicos se ven abocados a cierres temporales en múltiples eventos de protestas sindicales por impagos de salarios, no pagan proveedores ni las Empresas Prestadoras de Salud (EPS) privadas hacen los pagos a los hospitales generándose un círculo negativo que desfinancia el sector y afecta la prestación del servicio. En contraste, se promueve la vinculación masiva a través de dos sistemas (el contributivo y el subsidiado), pero el sistema no cuenta con la financiación suficiente ni el manejo adecuado para garantizar el acceso a la salud de toda la población. Incluso las organizaciones criminales se han apropiado de una parte de los recursos con la complicidad de políticos locales, alcaldes, gobernadores y de directores de hospitales. Recientemente el presidente Juan Manuel Santos (2010-2018) reconoció que entre 2002 y 2010 (en las dos presidencias de su antecesor Álvaro Uribe Vélez) los grupos paramilitares se habían apropiado de 530.000 millones, aproximadamente 250 millones de dólares de la época (Semana, 2-9 agosto, 2015). Por su parte, la cobertura en pensiones en el país es muy baja (1.600.000 pensionados) y se ha ido aumentando la edad mínima para pensionarse (57 años en las mujeres y 62 en los hombres) a la vez que las semanas cotizadas (mínimo 1300, equiva-

sobre formalidades establecidas por los sujetos de las relaciones laborales; garantía a la seguridad social, la capacitación, el adiestramiento y el descanso necesario; protección especial a la mujer, a la maternidad y al trabajador menor de edad".

${ }^{11}$ Se establece al respecto que "se garantiza a todos los habitantes el derecho irrenunciable a la Seguridad Social. El Estado, con la participación de los particulares, ampliará progresivamente la cobertura de la Seguridad Social que comprenderá la prestación de los servicios en la forma que determine la Ley. La Seguridad Social podrá ser prestada por entidades públicas o privadas, de conformidad con la ley. No se podrán destinar ni utilizar los recursos de las instituciones de la Seguridad Social para fines diferentes a ella. La ley definirá los medios para que los recursos destinados a pensiones mantengan su poder adquisitivo constante (Art. 48, Constitución Nacional). 
lentes a 27 años de cotizaciones). Además del sistema de prima media de la empresa estatal Colpensiones existen los fondos privados de pensiones y se ha transitado de un sistema basado en la garantía de un derecho a un sistema financiero de ahorro y los millonarios recursos de las cotizaciones son manejados por grandes grupos económicos.

Por otra parte, en educación hay un creciente proceso de privatización, la cobertura de instituciones privadas sobrepasa en amplio margen a la pública y el sistema educativo tiene una base amplia pero se va adelgazando progresivamente de tal forma que la movilidad social a través del acceso a la educación superior es muy limitada. El analfabetismo es del 6.4 por ciento entre los mayores de 15 años y las coberturas netas en educación básica y media son altas (del 88 por ciento en el 2013), aunque no el promedio de años de educación (8.25 años) ${ }^{12}$. En educación superior en 2013 había 32 universidades públicas y 49 privadas y de los 2.103 .331 estudiantes el 46 por ciento estaba matriculado en instituciones privadas; había 6 instituciones tecnológicas públicas frente a 38 privadas y 9 instituciones técnicas profesionales del Estado frente a 27 privadas. La tasa bruta de cobertura para el 2013 era del 45.5 por ciento, con altos niveles de deserción. ${ }^{13}$ Muchos acceden a la educación básica, una parte deserta y otras solo avanza hasta cierto grado accediendo solo una minoría a las universidades, de la cual una parte finalmente se gradúa. Ante las exigencias del mercado, las maestrías y doctorados son muy limitadas, la mayoría funciona en universidades privadas y tienen altos costos.

Así, las respuestas a las tres preguntas centrales indican déficits. La democracia colombiana es de baja calidad no solo en los procedimientos y en los procesos políticos, también en sus resultados. Los ciudadanos reciben muy poco de la democracia y el régimen político reproduce condiciones de amplia desigualdad, de exclusión y discriminación.

\section{Políticas, gestión pública y baja calidad democrática}

12 Ministerio nacional de Educación, Estadísticas del sector educativo. Disponible en línea: http://menweb.mineducacion.gov.co/seguimiento/estadisticas/principal.php?seccion=9\&id categoria $=2 \&$ consulta $=$ anos promedio $\&$ nivel $=9 \& \mathrm{dpto}=\& \mathrm{et}=\&$ mun $=\&$ ins $=\&$ sede $=$

13 Estadísticas del Ministerio Nacional de Educación a diciembre de 2013, disponible en línea en: http://www.mineducacion.gov.co/sistemasdeinformacion/1735/articles-212350_resumen.xls 
En Colombia un alto porcentaje de su población carece del acceso a bienes y servicios básicos, no cuenta con derechos sociales, económicos y culturales y desde las instancias gubernamentales no se ha dado respuestas a sus necesidades de tal forma que permitan ir superando esta realidad. La baja calidad de la democracia se manifiesta también en la inequidad social y en esta inciden, por una parte, las debilidades del Estado de derecho (la gran distancia que existe entre el formalismo que consagra derechos sociales de los colombianos con carácter constitucional y la efectividad de las políticas para implementar estos derechos) y la incapacidad del Estado para hacer efectiva la provisión de bienes y servicios básicos para la reproducción vital de los ciudadanos. La gestión pública en los diversos niveles del Estado y de las entidades territoriales y gubernamentales se orienta por criterios de reducción del Estado, de redimensionamiento de sus responsabilidades sociales en sectores clave como la educación, la salud y la seguridad social y de su papel en la economía. Asimismo, por el predominio de una gestión pública nacional y territorial que obedece a criterios privados y de beneficios a grupos y a sectores incorporados en redes de clientelas, faccionales y partidistas. El acceso a bienes y servicios pasa por la intermediación política y no obedece a políticas estatales universalistas de bienestar que le den contenido a la ciudadanía social.

Las deficiencias de las dimensiones procedimentales de la democracia colombiana se reflejan también en sus resultados: quienes son elegidos (en elecciones cuestionadas por la manipulación, el fraude, el clientelismo y la coacción) son cuestionados y sus decisiones, la gestión pública en su conjunto en diversos sectores y subsectores, la labor legislativa del Congreso, la planeación del desarrollo y la formulación, ejecución e implementación de políticas, no se concretan en mejores condiciones de vida para la mayoría de la población. La Constitución define al Estado Social de Derecho y hay orientaciones de políticas sociales y cierto avance en su aplicación, pero perviven grandes desigualdades en el acceso a bienes y servicios, persiste una enorme desigualdad social. Retomando la dimensión IV del Índice de Desarrollo Democrático de la Fundación Poli- 
lat respecto al ejercicio de poder efectivo para gobernar, se observa que Colombia presenta en la última década valores muy bajos, de igual forma que todos los países de América latina. Este índice incorpora la asignación de recursos en sectores claves como la salud y en educación, los índices de escolaridad, de matrícula, de mortalidad infantil y la población bajo línea de pobreza ${ }^{14}$. De sus resultados se desprende como conclusión, una baja capacidad para hacer un uso eficiente de los recursos de tal forma que propicien un mejoramiento apreciable en las condiciones de igualdad y desarrollo de ciudadanía social y económica. Esta incapacidad de gestionar las necesidades colectivas para generar mejores condiciones de vida para la población hacen que la democracia colombiana, deficitaria en sus dimensiones estrictamente políticas, sea también de baja calidad en sus resultados, en su capacidad para generar políticas que aseguren bienestar (ver gráfica 1).

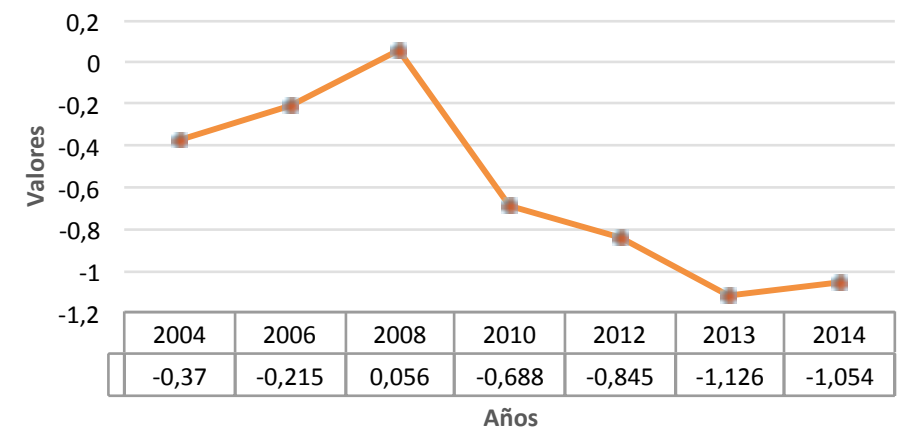

Hay siete aspectos centrales que hacen que las decisiones en democracia no conduzcan a un mejoramiento de las condiciones de vida de la población en los términos que se pueda hablar de una democracia de calidad, esto es, con la concreción de condiciones básicas de bienestar y de ciudadanía social. Estos aspectos tienen que 14 Los indicadores son: desempeño en salud (mortalidad infantil y porcentaje del PIB en el sector); desempeño en educación (matricula en secundaria, porcentaje del PIB invertido en educación); desempleo urbano y población bajo línea de pobreza. Se mide de 0 a 10.0 (véase: http://www.iddlat.org/downloads/idd-lat-2012.pdf ). 
ver con decisiones que han tomado los poderes Legislativo y Ejecutivo a lo largo de las últimas décadas. En el análisis se consideran especialmente las del último cuarto de siglo (1991-2015), en el que el país ha sido gobernador por presidentes procedentes de estructuras de poder pertenecientes al bipartidismo Liberal y Conservador y, desde el año 2002, por liderazgos desagregados de estas, por presidentes que antes pertenecieron al partido Liberal y que tras su crisis interna decidieron incorporarse a nuevos partidos creados por desagregación de un sector de este y por incorporación de algunos nuevos sectores políticos de diversa procedencia. Se han mantenido los pilares económicos y sociales de un modelo de desarrollo que reproduce estructuras económicas de privilegios, mantiene la brecha entre ricos y pobres, pervive la exclusión social y la pobreza de un alto porcentaje de la población, reproduce la desigualdad social y de oportunidades, niega el acceso universal a bienes y servicios básicos para la mayoría de la población.

Aunque la Constitución de 1991 trazó los principios básicos que debieron haber dado paso al inicio de la construcción de un modelo de sociedad basada en el Estado Social de Derecho, las políticas y programas gubernamentales y las decisiones legislativas van en gran medida en la vía opuesta, de tal forma que en un cuarto de siglo la democracia colombiana, limitada y defectuosa en sus procedimientos, se muestra de muy baja calidad en sus resultados. Estos seis aspectos son (a) un sistema tributario regresivo que no permite redistribuir los beneficios sociales para generar un mínimo bienestar social y que, por el contrario, tiende a generar concentración de la riqueza y a ampliar la brecha entre ricos y pobres; (b) una mala calidad del gasto social, en su asignación y en su eficacia para producir bienestar social; (c) una política laboral que frente a las dificultades y limitaciones del sistema productivo para incorporar nuevos obreros, empleados, funcionarios y las consecuentes altas tasas de desempleo, ha flexibilizado el mercado laboral de tal forma que la informalidad es cada vez mayor, con su respectiva ausencia de seguridad social; (d) la desigualdad en el acceso a la propiedad de la tierra, la ausencia de políticas sobre tributación de la gran propiedad 
y de sanciones al uso ocioso, además de la expropiación violenta de miles de propietarios por partes de actores armados ilegales que ha contribuido a la alta concentración; (e) el predominio de un sistema de intermediación y de gestión pública clientelar y patrimonialista; (f) la corrupción y captura parcial del Estado por las organizaciones criminales en asocio con amplios sectores de la clase política y de los gobernantes locales que conduce a que una parte importante de los recursos públicos sean apropiados por particulares a través de formas ilegales. En el análisis se incluyen los gobiernos de las dos últimas décadas que abarcan las presidencias de César Gaviria (1990-1994), Ernesto Samper (1994-1998), Andrés Pastrana Arango (1998-2002), Álvaro Uribe Vélez (2002-2006 y 2006-2010) y Juan Manuel Santos (2010-2014 y 2014-2018).

Como se ha señalado en recientes estudios, entre ellos el de la CEPAL, la política fiscal tiene un claro impacto distributivo: los ciudadanos reciben poco o mucho de las decisiones que se toman en las democracias y estas decisiones se concretan en sus mejores o peores condiciones materiales de vida. Es claro también que la acción del Estado incide en los niveles de desigualdad de ingresos imperantes en una economía a través de medidas como el establecimiento de mínimos salariales, la negociación entre trabajadores y empresas, y la regulación de los grados de concentración en los mercados de bienes y servicios, entre otras medidas, tienen consecuencias directas sobre la desigualdad del ingreso primario, como suele denominarse al ingreso que surge del mercado. Es decir que la distribución que resulta de la producción y el mercado no es inexorable. Las intervenciones públicas redefinen la distribución generada por el mercado por medio de instrumentos como los impuestos y las transferencias, los cuales tienen una incidencia directa en la distribución del ingreso disponible de los hogares (Amarante y Jiménez, 2015, p. 27). En esta misma dirección, se plantea que una parte muy importante de la acción redistributiva del Estado tiene lugar a través de mecanismos que pueden considerarse indirectos, como el gasto público en educación y salud que tienen un impacto muy relevante en tanto que promueven las capacidades humanas y facilitan la inserción futura en el mer- 
cado de trabajo. El citado trabajo señala que en reciente análisis del efecto de las políticas en la reducción de la desigualdad varía de un país a otro: mientras que en Argentina, Brasil y Uruguay el conjunto de instrumentos analizados reduce el índice de Gini en un promedio de 7 puntos, destacándose el significativo impacto de las pensiones públicas, en otros países como Chile, Costa Rica y México, se observan reducciones superiores a la media, pero explicadas, fundamentalmente, por la acción de transferencias y subsidios directos. En un tercer grupo de países (Colombia, El Salvador, el Paraguay y la República Dominicana) el impacto del impuesto a la renta y las transferencias, en promedio, solo reduce un punto el índice de Gini. Este estudio del 2011 concluyó al respecto que "las instituciones en la región no logran limitar (ex ante) las dinámicas de mercado que genera la concentración del ingreso y la capacidad que tienen de corregirla (ex post) a través de transferencias monetarias e impuestos es limitada, sobre todo si se compara con las experiencias de otros países o regiones. Esta menor capacidad tiene que ver con los bajos niveles de ingresos tributarios y su menor impacto distributivo, así como con los menores y menos progresivos niveles de transferencias, incluidas las contributivas" (Amarante y Jiménez, 2015, p. 27)

El estudio citado retoma otros análisis precedentes que concluyen que los sistemas tributarios de América Latina siempre han jugado un papel redistributivo modesto e incluso han llegado a ser globalmente regresivos. Ya sea por el diseño tributario sesgado a favor de las rentas del trabajo, la elevada evasión, los beneficios impositivos o la mayor capacidad para eludir obligaciones tributarias, las personas más ricas no han sido gravados de acuerdo con su nivel de ingresos o riqueza y en ocasiones pagan comparativamente menos impuestos que otros contribuyentes de menores rentas. Además, los sistemas tributarios dependen mucho del componente indirecto de imposición al consumo, que resulta regresivo. Los impuestos más progresivos resultan ser los directos, entre los que se destacan el impuesto a la renta personal y, en menor medida, el impuesto a la renta de las sociedades, seguidos por los impuestos a los bienes personales y al patrimonio y los más regresivos son las contribuciones a la 
seguridad social, los gravámenes sobre los cigarrillos y las bebidas alcohólicas, el impuesto al valor agregado (IVA)(CEPAL/IEF, 2014; Gómez Sabaíni, Jiménez y Podestá, 2010).

En este marco, en Colombia el IVA ha ido aumentando su peso como porcentaje del PIB, mientras que en 1995 era el 3.7\%; en 2000 del 4.1\%; luego pasó en el 2003 al 5.2; en el 2005 al 5.4\% y en el 2010 del $5.8 \%$. En cuanto a la tarifa general, se ha duplicado en cuatro décadas: en la década de 1970 era del $8 \%$ y excluía a muchos productos; en 1984 era del 10\%; con la reforma de 1990 pasa al 12\%; en 1992 pasa al $14 \%$ y en 1995 al $16 \%$, se mantiene con una nueva reforma en el 2000, con la nueva reforma del 2002 se amplía la base pasa al 16 en algunos productos y del $20 \%$ en telefonía celular, una nueva reforma en 2003 incluye otros bienes. Actualmente del 16\% es la tarifa general aplicada a todos los bienes con excepción de los excluidos o de las tarifas preferenciales, en cuatro décadas se ha duplicado la tarifa general, se amplió la base con nuevos productos y servicios ${ }^{15}$ (Dian, 2012). ${ }^{15}$ Entre 1990 y 20114 se han realizado doce reformas tributarias en Colombia: con la Ley 49 Reforma Tributaria de 1990 se redujo el número de contribuyentes obligados a declarar, aumentó la base del IVA, se eliminaron exenciones y una tarifa general del $10 \%$ al $12 \%$, continuaron las Otros: Reducciones arancelarias de la apertura económica. Con la Ley 6 de 1992 aumentó la base del IVA, se excluyó a los bienes de la canasta familiar con una tarifa general del $12 \%$ al 14\%, se eliminó el impuesto al patrimonio. Con la Ley 223 de 1995 se elevó la tarifa del IVA al 16\%, se creó el impuesto global a la gasolina. Con la Ley 488 de 1998 se exonera los ingresos de las EICE, cajas de compensación y fondos gremiales, se impuso el IVA al transporte aéreo nacional, una tarifa general al $15 \%$ a finales de 1999 , se creó el impuesto a las transacciones bancarias del 2 X 1000 temporal. Con la Ley 633 de 2000 se impuso también el IVA al transporte aéreo internacional, transporte público, cigarrillos y tabacos. Tarifa general del 16\% y aumentó el impuesto a las transacciones al 3 X 1000 permanente. Con la Ley 788 de 2002. Se crea la sobretasa a la renta del $10 \%$ en 2003 y $5 \%$ desde 2004 . Nuevas rentas exentas y en el IVA ampliación de la base. Aumento de tarifa de $10 \%$ a 16\% para algunos bienes. Tarifa de $20 \%$ para telefonía celular. Con la Ley 863 de 2003 se establece una sobretasa en renta del 10\% (2004-2006).Creación de la deducción por inversión del 30\%. En el IVA algunos excluidos pasan a ser gravados al 7\% y nuevas tarifas del $3 \%$ y $5 \%$ (cerveza y de suerte y azar). El impuesto a las transacciones bancarias pasa al $4 \mathrm{X}$ 1000 (2004-2007). Con la Ley 1111 de 2006 se elimina la sobretasa a partir del 2007, se elimina el impuesto de remesas y en el IVA algunos bienes pasan del 10\% al 16\%, impuesto la patrimonio a partir de 2007 (tarifa de 1.2\% del patrimonio > \$3000 millones) se vuelve permanente el 4 X 1000 . Con la Ley 1370 de 2009 se reduce del 40\% al 30\% la renta de las inversiones en activos fijos productivos, se establece el impuesto la patrimonio a partir de 2011, (tarifa de $2.4 \%$ del patrimonio $>\$ 3000$ millones y del $4.8 \%$ para patrimonios $>\$ 5000$ millones) - ocho cuotas iguales entre 2011 y 2014. Con la Ley 1430 de 2010 se elimina la deducción por inversión, se propone cerrar focos de evasión y eliminación progresiva del GMF: 2 X 1000 en 2014, 1 X 1000 en 2016 y desaparecerá en 2018. Fiscalización de la DIAN al recaudo de IVA, retención a pago de intereses de crédito externo, eliminación de la sobretasa del $20 \%$ al consumo de energía eléctrica del sector industrial. Con la Ley 1607 de 2012 se crea el impuesto sobre la Renta para la Equidad (CREE) como el aporte con el que contribuyen las sociedades y personas jurídicas y asimiladas para el ICBF. Impuestos a personas naturales, impuestos a las sociedades, reforma del Impuesto al Valor Agregado -IVA, e impuesto al consumo, ganancias ocasionales, y normas anti evasión y anti elusión. La Ley 1607 de 2013 establece el Impuesto sobre la renta para personas naturales. Se establece una clasificación de personas naturales en empleados y trabajadores por cuenta propia. Creación de dos sistemas presuntivos de determinación de la base gravable de Impuesto Mínimo Alternativo -IMAN e Impuesto 
El carácter regresivo del IVA en Colombia ha sido argumentado por diversos estudios, entre estos el realizado por Fedesarrollo (Steiner y Cañas, 2013). Para los investigadores el impuesto es abiertamente regresivo y lo demuestran con datos contundentes: el 35\% de la exención se la llevan los hogares del decil más rico, mientras que los hogares más pobres presentan tasas efectivas (medidas sobre el ingreso) superiores a la de los hogares más ricos, esto se refleja en el hecho de que el 4,4\% del ingreso de los hogares más pobres corresponde al pago del IVA, mientras que para los hogares más ricos este pago representa tan sólo el 2,8\% del ingreso del hogar. Así, el aumento progresivo en las últimas décadas ha beneficiado a quienes tienen mayores ingresos, un impuesto que impone la misma tarifa a los productos sin tener en cuenta las diferencias entre quienes lo pagan y que ha llegado a tener una amplia cobertura en bienes y servicios. En cuanto al impuesto de renta, los mismos investigadores detectan la existencia de una base tributaria muy estrecha que excluye la mayor parte la población del pago del impuesto, lo cual ha conducido a que el recaudo se concentre en las empresas (o personas jurídicas) --80\% frente a 20\% asumido por las personas-- lo que contrasta, por ejemplo, con la distribución de la carga en la OECD, donde el $24 \%$ lo pagan las empresas y el $76 \%$ de las personas. Este tipo de impuesto es poco progresivo por que terminan siendo trasladados a los consumidores o porque la propiedad de las empresas es muy dispersa o porque se trata de firmas pequeñas.

A estas dos consideraciones negativas (regresivas) de los dos principales impuestos se le adiciona una amplia política de beneficios tributarios que son una fuente de inequidad horizontal entre sectores de la economía, distorsionan la asignación de recursos y van en contravía del principio de simplicidad. Además del costo fiscal, que para el año 2011 fue de $0,6 \%$ del PIB; $63 \%$ corresponde a rentas exentas, $21 \%$ a descuentos tributarios y $15,5 \%$ a la deducción de acti-

Mínimo Alternativo Simple. El primero de enero de 2013 solamente estará permitido cobrar tres valores del IVA: $0 \%$ que se debe aplicar para toda la canasta básica familiar; $5 \%$ para la medicina prepagada que antes estaba en 10\%. El 5\% también será para algunos alimentos procesados como embutidos. Restaurantes que operan como franquicia y grandes cadenas pagarán un impuesto al Consumo del 8\%. Con la Ley 1607 de 2014 se mantuvo gravamen a los Movimientos Financieros (GMF) con una tarifa de 4X1.000 hasta 2018, para iniciar su desmonte gradual a partir de $2019 \mathrm{y}$ se creó el impuesto a la riqueza: estará a cargo de las personas jurídicas, naturales y sociedades de hecho contribuyentes del impuesto sobre la renta y complementarios (Dinero, febrero 27 de 2015 "Las 12 tributarias de Colombia"). 
vos fijos. ${ }^{16}$ Los contratos de estabilidad jurídica son una puerta para perpetuar la inequidad. A través de éstos se puede asegurar la continuidad de aquellas normas, tributarias y de otro tipo, vigentes en (Steiner y Cañas, 2013). Durante los dos gobiernos de Álvaro Uribe Vélez (2002-2010) se implementó una política de amplias exenciones a los empresarios, entre ellos en el sector de la minería en el que se expidieron decenas de licencias y se exoneraron del pago de impuestos a numerosas empresas. El sector minero ha sido el principal beneficiario de los incentivos, seguido por el eléctrico, el de servicios financieros y las comunicaciones. Hasta el 2007 se calcula en 9.2 por ciento del PIB el peso de las exenciones, el más alto de América latina para el mismo periodo, seguido de México y Guatemala, de 6.3 y 7.3, respectivamente (Benson, 2011). También hay otras exenciones como a los dividendos o ganancias por rendimiento de las acciones en las empresas, a las pensiones de altos ingresos, los contratos de estabilidad jurídica, beneficios prolongados a la industria hotelera para atraer la inversión en algunas zonas y a la industria editorial y las grandes ventas accionarias tampoco pagan impuestos., existen zonas francas que se benefician de exenciones, aunque algunas de ellas tengan como principal mercado el interno y no el externo, motivo de su creación excepcional. La gran cantidad de exenciones implica una desigualdad en la carga tributaria, que tiende a recaer de forma excesiva sobre las empresas (renta, cree e impuesto de riqueza), lo cual afecta la productividad y la creación de empleos de buen a calidad.

\footnotetext{
${ }^{16}$ En Colombia la deducción tributaria más importante de la última década fue la deducción por inversión en activos fijos reales productivos que estuvo vigente desde 2003 hasta el año gravable 2010. Existen además deducciones por inversiones en investigaciones científicas o tecnológicas, en proyectos de inversión agroindustrial, en construcción de acueductos, en mejoramiento de fincas rurales y en inversión en librerías, entre otras; Se consideran rentas exentas los servicios hoteleros prestados en nuevos hoteles que se construyan dentro de los quince años siguientes a partir de 2002 así como los servicios hoteleros en hoteles que se remodelen y/o amplíen dentro de los quince años siguientes al 2002, por un término de 30 años. Asimismo, se considera renta exenta, por un período de quince años, la venta de energía eléctrica generada con recursos eólicos, biomasa o recursos agrícolas. Los intereses y demás pagos para empréstitos y títulos de deuda pública también disminuyen la base gravable, en forma de exenciones; Los contribuyentes del impuesto sobre la renta pueden afectar el monto a pagar del impuesto a través de los descuentos tributarios. Entre éstos podemos destacar el descuento por el pago del impuesto sobre las ventas en importaciones de maquinaria industrial para industrias básicas (minería, hidrocarburos, química pesada, metalurgia extractiva, generación y transmisión de energía eléctrica); el descuento por inversión en acciones de sociedades agropecuarias; y el descuento del $40 \%$ del valor de las inversiones que realicen las empresas de servicios públicos domiciliarios que presten servicios de acueducto o alcantarillado con el objetivo de garantizar la cobertura del servicio (Steiner y Cañas, 2013).
} 
Con el gobierno de Juan Manuel Santos la reforma tributaria de 2014 constituye un relativo avance en torno a la equidad al establecer el impuesto a la riqueza que se aplicará al patrimonio bruto menos las deudas del contribuyente que el primero de enero del 2015 sea igual o superior a 1.000 millones de pesos. Para las personas jurídicas tendrá vigencia hasta el 2017 y para las naturales, hasta el 2018. Estas últimas pagarán una tarifa de 0,125 por ciento sobre el patrimonio de entre 1.000 y 2.000 millones de pesos; de 0,35 por ciento entre 2.000 y 3.000 millones; de 0,75 por ciento entre 3.000 y 5.000 millones, y de 1,5 por ciento para más de 5.000 millones de pesos. El llamado impuesto sobre la renta para la equidad (Cree) queda permanente con una tarifa del 9 por ciento; además se crea una sobretasa para las utilidades superiores a 800 millones de pesos, a las que se les aplicará una tarifa del 5 por ciento en el 2015, del 6 por ciento en el 2016, del 8 por ciento en el 2017 y del 9 por ciento en el 2018. Se sigue planteando la necesidad de una reforma tributaria estructural, equitativa, que amplíe la base tributaria, que los impuestos no recaigan siempre sobre los mismos sectores y que incluya a los terratenientes y grandes propietarios que no pagan impuestos o pagan muy poco.

Además de la política fiscal regresiva generadora y reproductora de inequidad social, en Colombia la inversión o gasto social ha crecido en el último cuarto de siglo, pero se caracteriza por su ineficiencia y la baja calidad. Con la Nueva Constitución de 1991 se dio un giro en la concepción sobre la inversión social o el gasto público social (GPS) y por primera vez se definió a este tipo de gastos como más importantes que otros al considerarlo prioritarios. El GPS pasó del 8.2\% del PIB en 1990 al 15.2\% en 1997, gasto orientado a educación, salud, agua potable, vivienda y seguridad social (incluye pensiones, asistencia y bienestar), luego disminuyó y se mantuvo en promedio del $13.5 \%$ hasta el 2014. En términos comparados, el GPS de Colombia es muy inferior en la última década al de los países que en América latina presentan una democracia de mayor calidad como Brasil (25.7\%), Chile (14.3\%), Costa Rica (22.3\%), Uruguay (23.8\%), Panamá (16.8\%)(Cardona, 2011; Cepal, 2014). 
Diversos análisis coinciden en señalar que el gasto social como prioridad presupuestal fue una de las mayores innovaciones de la Constitución de 1991 y en los últimos años ha crecido la inversión en sectores sociales, no obstante, también señalan que no ha generado una mayor eficiencia social y ejn ello inciden varios factores: algunos subsidios del Estado benefician a clases medias y altas (como los subsidios a grandes propietarios de tierras o a empresarios del campo implementados por el programa Agro Ingreso Seguro del gobierno de Álvaro Uribe Vélez); también se incluyen las altas pensiones a congresistas, ex congresistas, magistrados, exmagistrados y otros altos funcionarios del Estado; el aumento de la inversión en educación se ha hecho sin exigir resultados en la calidad y se reproducen esquemas propios de sociedades con muy poca movilidad social; la inversión social fluye en muchos casos a través de partidas regionales en las que los congresistas intervienen como mediadores y una parte de los recursos termina en manos de particulares a través del reparto clientelistas, de contratos poco transparentes o inversiones focalizadas en zonas en las que los congresistas tienen sus nichos electorales. El gasto social se focaliza y reproduce privilegios y se implementa a través de mecanismos políticos de intermediación. Adicionalmente, existe la captura parcial del Estado por organizaciones criminales que se apropian de los recursos públicos y hay una extendida corrupción en municipios y departamentos que hacen que los dineros públicos terminen en manos de políticos y sus socios y allegados.

En cuanto a la política laboral, esta tiende a generar condiciones para que se reproduzca la informalidad y los empleos de muy baja calidad. La estructura económica colombiana presenta dificultades en la absorción de nueva fuerza laboral producto de una creciente desindustrialización, de la crisis del sector agrícola exportador, del desplazamiento hacia las ciudades de más de cinco millones de personas desarraigadas que llegan a las capitales y ciudades intermedias expulsadas de sus tierras y expropiadas por la presencia de actores armados ilegales y la presencia de un sector servicios sobredimensionado. Hay una clara diferenciación y un dualismo en el mercado laboral: por una parte, existe un sector reducido en el que hay buenos salarios, con educación 
superior y cualificado, con seguridad social y estabilidad, y por otra parte, un sector ampliamente mayoritario que vive en el día a día, sobrevive en la calle, en las ventas ambulantes, en el transporte ilegal, en las ventas en sus domicilios, en ventas por catálogos, en la ocupación del espacio público para revender productos de contrabando que proveen grandes empresarios ilegales. También cientos de profesionales como enfermeras, médicos, profesores, comunicadores sociales, docentes, economistas, que solo acceden a contratos de prestación de servicios que se han generalizado, a término fijo, sin garantías laborales, de corta duración, en el que deben pagar su propia seguridad social y no cuentan con garantías mínimas. Desde la Ley 50 de 1990 se empezó a flexibilizar las condiciones de contratación, se eliminó la retroactividad de las cesantías y se crearon los Fondos Privados de Cesantías y Pensiones, se generalizaron los contratos a término fijo, el empleo temporal y diversas modalidades de subcontratación, asimismo los salarios integrales que inicialmente estaban instituidos para salarios superiores a 10 salarios mínimos se generalizaron en los siguientes años como una forma de eludir las prestaciones sociales y la responsabilidad de las empresas con sus trabajadores que se califican como empleados independientes. Luego vinieron otras reformas en detrimento de los trabajadores como la establecida por el gobierno de Álvaro Uribe Vélez en la que se extendío la jornada diurna hasta las 10:00 de la noche con lo cual se dejaron de pagar los recargos nocturnos y se redujo el valor de los dominicales y festivos; también se redujeron los montos indemnizatorios en caso de despido sin justa causa (Ley 789 de 2002).

La combinación de una estructura limitada de la economía para generar empleos y a extrema flexibilización laboral, generaron un mercado laboral en el que cerca de dos terceras partes de los trabajadores en todos los sectores están en la informalidad, no tienen un contrato laboral, aunque muchos de ellos cumplen horarios, tienen responsabilidades y están calificados. Son empleados sin empleadores y esto funciona con base en la terciarización como una forma de eludir las responsabilidades de las empresas, grandes, pequeñas, medianas, incluso del Estado. De la terciarización hacen parte empresas de servicios temporales, cooperativas de trabajo asociado y 
órdenes directas de prestación de servicios, todas ellas permiten eludir pagos derivados de responsabilidades laborales contemplados en la ley (primas, vacaciones, cesantías, pago de seguridad social). Es una manera de volver informal a todos los trabajadores, incluidos algunos muy calificados como en el sector salud. Gran parte de los trabajadores colombianos sobreviven, no cubren sus necesidades básicas, no cuentan con acceso a seguridad social, no tienen empleadores aunque trabajan mucho, no tienen capacidad de ahorro, acceden a una educación pública de mala calidad y a servicios de salud congestionados y afectados por la desfinanciación. El economista y Ministro de Salud del gobierno de Juan Manuel Santos (2014-2018), Alejandro Gaviria, describía muy bien esta precarización laboral y su incidencia en la desigualdad social:

Uno podría decir que la desigualdad tiene como causa principal que la economía o la sociedad colombiana se está dividiendo en dos: un sector moderno donde se emplea los trabajadores con educación superior y un sector informal donde se refugian los trabajadores sin educación superior. Los dos tienen diferencias muy grandes no solamente en los salarios, sino en otras cosas que afectan los salarios reales de los trabajadores como capacitación, innovación, tamaño de los negocios. Los dos sectores son muy distintos y eso tiene consecuencias. En los últimos 15 años no se ha generado un solo empleo asalariado para los trabajadores sin educación superior, esto quiere decir que hay barreras muy grandes de entrada, una segmentación muy grande de nuestro mercado laboral. Y eso es tal vez la principal causa de lo que está pasando. Hay otras causas mucho más profundas y más complicadas. Tienen que ver con el legado colonial. Con la falta de igualdad de oportunidades y en especial, con la falta de acceso a la educación de calidad. También tiene que ver con los factores típicos de una sociedad latinoamericana, donde hay una elite - el $15 \%$ ó $20 \%$ de la población -, que tiene acceso a las mejores oportunidades, a los mejores colegios, al crédito, que tiene mayores oportunidades de beneficio económico, una cosa que está negada para el otro $80 \%$. Las causas de eso son políticas e históricas, más difíciles de combatir (Gaviria, 2011). 
No solo se refiere a la economía informal como generadora de inequidad también hay desigualdad de oportunidades que se expresa en el acceso desigual a la educación básica y a la educación superior, a la ausencia de meritocracia, al peso de las influencias políticas que posibilitan a algunos y niegan a otros el acceso a los cargos públicos y privados y que generan una alta dependencia de los profesionales. La alta informalidad y la economía de sobrevivencia tienen efectos en el manejo de las coberturas en pensiones y quienes cotizan a fondos privados o al fondo público, asimismo el sistema de salud incluye un enorme sector de régimen subsidiados que se asume con los aportes de quienes hacen parte del régimen contributivo y con los aportes del Estado. Se genera un círculo avieso difícil de superar. El gobierno de Juan Manuel Santos ha impulsado una política de formalización del empleo con estímulos a los empresarios como la abolición de los aportes parafiscales y de los aportes a la seguridad social de sus empleados (Ley 1607 de 20112). ${ }^{17}$ También se estableció la desaparición de las Cooperativas de Trabajo Asociado, con lo cual se pretendía acabar con la terciarización y que las empresas contrataran directamente y con todos los requisitos de ley a los empleados (Ley 1450 de 2011). En la práctica lo que ocurrió fue la generalización de la contratación a través de órdenes de servicios con supuestos salarios integrales. Muy pocas empresas hicieron la conversión en la contratación. El Estado es incapaz de regular las relaciones laborales y la pervivencia de la informalidad es una evidencia de ello.

Por otra parte, un aspecto central de las políticas públicas y de la labor legislativa en el país es la ausencia de una política agraria con carácter redistributivo y que impida la expropiación violenta de miles de campesinos propietarios o poseedores de tierras en zonas de violencia. Este es uno de los puntos nodales de la desigualdad social y del conflicto en Colombia. El Gini rural de Colombia es el más alto del mundo, pasó del 0.740 a 0.880 en el 2011. En cuanto a las políticas estatales, se considera que el 55 de los campesinos nunca han recibido asistencia pública, el $85 \%$ carece de alcantarillado y el $60 \%$ no tiene

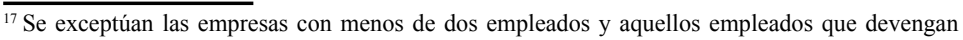
más de 10 salarios mínimos legales. Además, las empresas siguen haciendo aportes a las cajas de compensación familiar.
} 
agua potable, el ingreso promedio es la tercera parte del ingreso de quienes viven en las ciudades, el analfabetismo es del 18.5\% (Semana, 2012). Según el Censo Agropecuario de 2015 Colombia sigue siendo un país con alta concentración de la propiedad rural: el 69,9 por ciento de las propiedades tiene menos de 5 hectáreas y ocupan solo el 5 por ciento del área censada, mientras que terrenos de más de 500 hectáreas están en manos del 0,4 de los propietarios y representa el 41,1 por ciento de las 113 millones hectáreas censadas. Otros datos indican que el 83,3 por ciento no tiene maquinaria para realizar su actividad y el 89 por ciento de los habitantes del sector rural nunca ha solicitado préstamos y la pobreza multidimensional es del 44.7 por ciento, los campesinos son el grupo poblacional con menores oportunidades de la sociedad colombiana (El Tiempo, Agosto 11 de 2015).

Un informe del Programa de las Naciones Unidas para el Desarrollo (PNUD) del 2011 había señalado la necesidad un replanteamiento de fondo en la política agraria en el país al considerar que no basta una reforma agraria, y que era necesario cambiar la estructura de la tenencia de la tierra, históricamente concentrada, pero también hacer un censo agrario -no se hace desde hace 40 años- y actualizar el catastro, sino gravar con impuestos altos a los dueños de mucha tierra y multar la improductiva, para desestimular la concentración (Portafolio, 2011). Durante el último lustro esta y otras voces que han insistido en el papel de la estructura de propiedad de la tierra y la débil presencia estatal en las áreas rurales en el conflicto armado, han sido escuchadas y en las actuales negociaciones de paz entre el gobierno de Juan Manuel Santos y las Fuerzas Armadas Revolucionarias de Colombia (FARC) este punto ha sido uno de los más importantes.

Recientemente se aprobó la Ley de Víctimas y Restitución de Tierras (Ley 1448 del 2011) en la que se establece que el Estado adoptará las medidas requeridas para la restitución jurídica y material de las tierras a los despojados y desplazados, y de no ser posible la restitución, para determinar y reconocer la compensación correspondiente. También se determinó que en el caso de bienes baldíos se procederá con la adjudicación del derecho de propiedad a favor de la persona que venía ejerciendo su explotación económica si durante el 
despojo o abandono se cumplieron las condiciones para la adjudicación. La restitución jurídica del inmueble despojado se realizará con el restablecimiento de los derechos de propiedad o posesión, según el caso. El restablecimiento del derecho de propiedad exigirá el registro de la medida en el folio de matrícula inmobiliaria. En el caso del derecho de posesión, su restablecimiento podrá acompañarse con la declaración de pertenencia (Art. 72). Esta ley es de gran alcance y se enmarca en el proceso de negociaciones de paz adelantado con las FARC en el que por primera vez en más cinco décadas de conflicto se reconoce a las víctimas y se asume su resarcimiento. ${ }^{18}$ Hasta finales del 2014 se habían restituido 84.516 hectáreas a 11.410 personas, además las familias han recibido ayudas.

En las negociaciones de paz de La Habana se acordó en el punto 1 de la agenda crear un Fondo de tierras de distribución gratuita para los campesinos sin tierra o con tierra insuficiente. No sólo de entregarle tierra al que no tiene, sino de darle "acceso integral": que la tierra esté acompañada de riego, crédito, asistencia técnica, y apoyo para la comercialización. También el acceso a la tierra incluye también ofrecer un subsidio integral y crédito especial para la compra de tierra, así como garantizar derechos de propiedad. Se acordó impulsar un plan masivo de formalización de la pequeña y mediana propiedad, y la creación de una jurisdicción agraria para asegurar la

\footnotetext{
${ }^{18}$ Se estableció como principios de la restitución de tierras los siguientes: (1) Preferente. La restitución de tierras, acompañada de acciones de apoyo pos-restitución, constituye la medida preferente de reparación integral para las víctimas. (2) Independencia. El derecho a la restitución de las tierras es un derecho en sí mismo y es independiente de que se haga o no el efectivo el retorno de las víctimas a quienes les asista ese derecho. (3) Progresividad. Se entenderá que las medidas de restitución contempladas en la presente ley tienen como objetivo el de propender de manera progresiva por el restablecimiento del proyecto de vida de las víctimas. (4) Estabilización. Las víctimas del desplazamiento forzado y del abandono forzado, tienen derecho a un retorno o reubicación voluntaria en condiciones de sostenibilidad, seguridad y dignidad. 5. Seguridad jurídica. Las medidas de restitución propenderán por garantizar la seguridad jurídica de la restitución y el esclarecimiento de la situación de los predios objeto de restitución. Para el efecto, se propenderá por la titulación de la propiedad como medida de restitución, considerando la relación jurídica que tenían las víctimas con los predios objeto de restitución o compensación. (6) Prevención. Las medidas de restitución se producirán en un marco de prevención del desplazamiento forzado, de protección a la vida e integridad de los reclamantes y de protección jurídica y física de las propiedades y posesiones de las personas desplazadas. (7) Participación. La planificación y gestión del retorno o reubicación y de la reintegración a la comunidad contará con la plena participación de las víctimas. (8) Prevalencia constitucional. Corresponde a las autoridades judiciales de que trata la presente ley, el deber de garantizar la prevalencia de los derechos de las víctimas del despojo y el abandono forzado, que tengan un vínculo especial constitucionalmente protegido, con los bienes de los cuales fueron despojados. En virtud de lo anterior, restituirán prioritariamente a las víctimas más vulnerables, y a aquellas que tengan un vínculo con la tierra que sea objeto de protección especial (Ley 1448 de 2011, art. 73).
} 
protección judicial eficaz a los derechos de propiedad de los campesinos y de todos los habitantes del campo. Asimismo, el Gobierno definirá lineamientos generales de uso del suelo que tengan en cuenta su vocación y pondrá en marcha programas de reconversión.

También la formación y actualización del catastro y la puesta al día del predial (“el que más tiene, más paga") creará los incentivos para darle un uso más productivo a la tierra. En cuarto lugar, se reconstruirán las regiones más afectadas por el conflicto y la pobreza con verdaderos planes de desarrollo que transformen esos territorios, garanticen derechos y faciliten la reconciliación. Se construirán de manera participativa planes de acción para la transformación regional. En quinto lugar, un combate a la pobreza rural: Un tercer pilar son planes nacionales que deberán lograr una reducción radical de la pobreza y la eliminación de la pobreza extrema. Estos planes están orientados a proveer bienes y servicios públicos en infraestructura (vías, distritos de riego, electricidad, conectividad), desarrollo social (planes especiales de salud, educación, vivienda y agua potable para el campo,) y estímulos de todo tipo a la productividad de la agricultura familiar (asistencia técnica, promoción del cooperativismo, líneas especiales de crédito, seguros subsidiados de cosecha, asociaciones solidarias para la comercialización, entre otros) y a la formalización laboral. En sexto lugar, un sistema especial de seguridad alimentaria y nutricional: se fortalecerán los mercados locales y regionales, se harán campañas para un manejo adecuado de alimentos por parte de las familias y se aplicarán programas especiales contra el hambre (Oficina del Alto Comisionado para la Paz, 2014). Hay sectores sociales y gremios de la economía que se oponen a estos acuerdos, entre estos quienes se han beneficiado de la apropiación ilegal y quienes se niegan a legitimar los acuerdos de paz. El acuerdo final está pendiente y hasta ahora son acuerdos parciales.

Los anteriores aspectos que denotan características centrales de la gestión pública y del resultado de la toma de decisiones en los poderes públicos (Ejecutivo y legislativo) están relacionados con un quinto aspecto central de la democracia relacionado con los modos de obrar político, con la presencia de políticos de negocios 
y de partidos que actúan como facciones de clientela y grupos que se disputan el reparto de recursos y de influencia en el Estado para favorecer a sus integrantes, allegados y socios políticos. Los partidos operan como agrupaciones de congresistas, de líderes políticos regionales, de operadores políticos populares y barriales articulados en redes de clientela cuyos líderes aspiran acceder a cargos de elección regional y nacional o mantenerse en ellos y su labor política se orienta a favorecer segmentos específicos de la población en las zonas y sectores sociales en donde encuentran respaldo electoral. No se representan intereses generales sino de fragmentos de la población y la intermediación de las facciones y de sus líderes consiste en gestionar recursos, empleos, auxilios o sobvenciones del Estado para sus seguidores y su clientela. Por esta vía en una sociedad con severas limitaciones en la provisión de bienes y servicios acceden a estos quienes estén integrados a redes políticas clientelares. En detrimento de políticas y programas con cobertura general, la gestión se orienta a solucionar problemas localizados, específicos, necesidades puntuales territoriales, comunales, sectoriales. El Estado como responsable de la provisión de ciertos bienes y servicios para todos los ciudadanos, es desplazado y reemplazo por la gestión del patrón político que canaliza recursos y los direcciona según sus intereses y de los de sus allegados y apoyos electorales. Una parte de los recursos termina financiando las campañas, o en manos de los operarios políticos que reciben retribuciones con recursos públicos.

Con el clientelismo la gestión pública democrática se distorsiona. En muchos de los 32 departamentos la clase política se ha mantenido en espacios de poder recurriendo a modos de obrar que incluyen el clientelismo, el patrimonialismo, el nepotismo, la intermediación en la contratación, las relaciones turbias con contratistas y empresarios. En departamentos de la costa Atlántica (La Guajira, Magdalena, Cesar, Atlántico, Bolívar, Córdoba,) y de la región del Pacífico (Chocó) es común encontrar integrantes de las familias políticas y de sus asociados en cargos importantes del departamento o de los municipios y en los institutos descentralizados. La gestión pública privatizada y los recursos colectivos usados de forma pri- 
vada para el beneficio de pocas familias y de sus allegados y socios políticos. En otros departamentos el clientelismo opera con base en nuevos liderazgos políticos producto de la competencia y de surgimiento de nuevos partidos desde comienzos de la década del 2000, cuando el sistema de partidos transitó del viejo bipartidismo a un multipartidismo por desagregación de nuevos partidos de los tradicionales Liberal y Conservador y algunas nuevas agrupaciones surgidas de la agregación de congresistas y políticos locales. En las elecciones nacionales de 2010 y 2014 se han mantenido 14 partidos, la mayoría de estos son la expresión de la agregación de facciones de clientela y operan en la lógica de intermediación particularista.

La otra característica señalada se asocia a estos modos de obrar político clientelares, solo que expresa también la asociación con la criminalidad a través de la captura parcial del Estado por parte de políticos de negocios, facciones partidistas y organizaciones criminales. La política se convierte en un negocio, como otro cualquiera, y esto implica que se debe obtener riqueza de forma ampliada, constante y frecuente. "los políticos de negocios no tienen la preparación ni la formación ideológica que les permita cumplir con tareas requeridas por la administración pública ni tampoco una identidad colectiva formadas por medio de una comunidad de intereses. Consideran a la política como un medio para incrementar sus propios recursos económicos"19.

Los políticos de negocios y su relación con la corrupción están asociadas a las redes de poder, no se trata de individuos aislados actuando por su cuenta y riesgo. Las redes de poder pueden ser descritas a partir de la idea de pares de nodos interconectados por conexiones que representan relaciones formales, informales y organizacionales $^{20}$. El tipo de conexiones que se establecen en la red determina su densidad y una red puede describirse como un plexo de relaciones entre actores que tienen vínculos con mayor o menor cercanía y están interconectados de formas más o menos directas: una red es más densa en tanto más actores hagan parte de ella y por

\footnotetext{
${ }^{19}$ Idem, p. 27

${ }^{20}$ White, Douglas R (1994), “Enfoque de redes para el estudio de comunidades urbanas", Estudios Demográficos y Urbanos, Vol. 9, Núm. 2. Mayo-Agosto. pp. 303-326.
} 
los nexos que tengan estos entre sí. Las conexiones entre nodos o actores representan puntos de coincidencia y pertenencia o un interés común (poder político y sus beneficios). En la red no todos los nudos (actores) tienen igual importancia, esta depende del rol y de la centralidad que tengan en ella, las personas que se ubican en la intersección de grupos entrecruzados tienen mayor influencia porque se convierten en un nodo central con la capacidad para movilizar recur$\operatorname{sos}^{21}$. Una red de corrupción conecta a diversos tipos de actores: políticos elegidos popularmente; funcionarios en diversos niveles que cumplen roles específicos; empresarios o grupos de presión. Las formas de corrupción van desde evitar multas y sanciones por una infracción hasta obtener la adjudicación de una licitación de obras públicas, pasando por la contratación indebida, la malversación de recursos públicos, la falsedad en documentos, los sobornos y otras múltiples formas de apropiación de recursos públicos.

La captura parcial del Estado incluye a redes y organizaciones criminales, a los políticos de negocios y a los partidos políticos, también capturados parcial o totalmente por las organizaciones criminales: la captura instrumental de los partidos políticos ${ }^{22}$. Los partidos se convierten en medios para instrumentar y hacer efectivos intereses particulares, privados y de grupos, algunos con actores legales y otros con organizaciones ilegales y criminales, esto se concreta a través de diversas acciones como la financiación condicionada a retribuciones por parte del partido y del candidato; la presión sobre los electores para que apoyen un candidato o renuncien a expresar libremente sus preferencias políticas; la coacción y la violencia contra los competidores.

Hay una relación inversamente proporcional entre la institucionalización partidista y la captura por parte de organizaciones criminales: a menor institucionalización organizativa mayor exposición a la captura instrumental por parte de organizaciones redes y criminales. Si predominan partidos centrados en los liderazgos y/o en los congresistas, con débiles estructuras organizativas, sin enraizamiento en la sociedad y sin un sistema de financiación estatal que

${ }^{21}$ Schmidt, Samuel y GIL, Jorge (1994), La red de poder en México, Este País, No. 44, Nov. (1993), "La Red de Poder Mexicana: El Caso de Miguel Alemán”, Revista Mexicana de Sociología, No. 3, pp. 103-117.

${ }^{22}$ Idem. 
ejerza controles, se amplían los espacios para la influencia por parte de actores externos legales (sindicatos, iglesias, gremios) o ilegales (mafias del narcotráfico, organizaciones de contratistas que operan en los bordes de la legalidad, grupos armados ilegales). Los partidos actúan como facciones o grupos de poder familiar, clientelar, de allegados y de apoyos de diversa índole, en procura de apoderarse de las esferas y espacios de gestión para beneficios particulares. La gestión pública se convierte en una fuente de enriquecimiento personal y de grupo y en un medio para apoderarse de los recursos públicos que pierden su carácter colectivo y pasan a ser manejados con criterios patrimoniales y de apropiación privada ilegal.

En contextos con partidos débilmente institucionalizados las organizaciones criminales, contratistas individuales, empresas interesadas en contratar con el Estado, mafias y redes subnacionales, buscan capturar a los partidos como un medio e instrumento para la captura del Estado y para su manipulación. Se trata de la Captura Instrumental de los Partidos Políticos (CiPP). No es capturar a los partidos como escenarios y organizaciones de poder, sino hacerlo para capturar parcialmente al Estado a través de ellos ${ }^{23}$.

En síntesis: las políticas y la gestión públicas referidas al ámbito de las decisiones de parte de los gobernantes, de los legisladores y de los funcionarios no han conducido en Colombia a la superación de las barreras estructurales que impiden el desarrollo social y la disminución de las desigualdades sociales. La democracia se hace imperante e irrelevante. Las decisiones reproducen privilegios y estructuras de desigualdad, exclusiones.

\section{CONSIDERACIONES FINALES}

A comienzos del 2010 un informe de la CEPAL señalaba "Sólo será posible mejorar la situación de seguridad de nuestros países con más y mejor Estado, con más y mejor política, con más y mejor gestión" (Cepal, 2010). En esta dirección el análisis que hemos planteado se orienta a sustentar que hay una directa relación entre

${ }^{23}$ Garay, Luís Jorge y Salcedo-Albarán, Eduardo, op.cit. 
estatalidad y democracia, y entre las características de los partidos y de la clase política y la democracia. La democracia colombiana es de baja calidad no solo en las dimensiones procedimentales, las que han sido consideradas tradicionalmente relacionadas con la democracia política, también presenta una baja calidad en sus resultados, específicamente respecto a la igualdad. A partir de indicadores básicos de desarrollo social, de inclusión/exclusión social y del acceso a bienes y servicios se ha mostrado cómo los ciudadanos colombianos -la mayoría de ellos- reciben muy poco de la democracia.

En las tres dimensiones señaladas por la Cepal la situación de Colombia es deficitaria. El nivel de estatalidad es muy bajo y el Estado colombiano ha sido incapaz de mantener el monopolio del uso de la fuerza y muchos actores armados ilegales le disputan el uso de las armas, el control territorial, la regulación social y el mantenimiento del orden social. Asimismo, dado los altos niveles de impunidad y disfuncionalidad de la justicia y la corrupción extendida en todos los niveles territoriales y esferas del poder público, se ha mostrado impotente para regular las relaciones sociales y mantener un uso racional y depurado de los recursos públicos y, algo fundamental en el tema analizado, no garantiza el acceso a bienes y servicios vitales para sus ciudadanos. En cuanto a las políticas, estas se han orientado sobre la base de un modelo de desarrollo que reproduce las desigualdades sociales, por el sistema de tributación, el favorecimiento al capital y a sectores sociales privilegiados económicamente, la desregulación laboral, la ausencia de políticas redistributivas y de acceso a la propiedad de la tierra. Y en la gestión las cosas no han sido mejores, el manejo de los asuntos públicos depende de los modos de obrar político predominantes signados por el clientelismo, el patrimonialismo y los privilegios para pequeños círculos de poder; y está ampliamente permeado por la corrupción.

Desde el enfoque del análisis de la calidad de la democracia se considera que no es posible avanzar mucho en el logro de una democracia de calidad si no se erige un Estado que pueda sostener con éxito el orden social, la protección de los ciudadanos, la equidad social, la defensa de los derechos humanos, la protección de los de- 
rechos sociales y políticos, el combate a la corrupción. El Estado se convierte en el espacio de los límites y alcances de la democracia, lo que permea el funcionamiento de la misma (Licea, 2011).

Un alto nivel de estatalidad y una alta calidad de la democracia están asociados y, viceversa, la debilidad estatal está correlacionada con la baja calidad de la democracia. Aquí adquiere relevancia la insistencia de Guillermo O'Donnell sobre la necesidad de un estado sin asimetrías como fundamento de la democracia. En este sentido, las deficiencias estatales en Colombia constituyen el eje central de su precariedad democrática. Asimismo, la naturaleza de sus partidos y de la mayoría de su dirigencia política, depredadora y buscadora de rentas públicas para su interés personal, son el otro elemento central que opera como barrera al desarrollo de la democracia.

\section{REFERENCIAS}

AMARANTE, V.; JIMÉNEZ, J. P. Desigualdad, concentración y rentas altas en América latina. En: JIMÉNEZ, Juan Pablo. Desigualdad, concentración del ingreso y tributación sobre las altas rentas en América latina. Ed. Naciones Unidad-Cepal, Santiago de Chile, 2015, pp.13-48. Disponible In: http://repositorio.cepal.org/ bitstream $/$ handle $/ 11362 / 37881 / \mathrm{S} 1420855$ _es.pdf?sequence=

ÁMBITO JURÍDICO. Más de 84.000 hectáreas se han restituido a víctimas del conflicto: URT. Noviembre 28 de 2014. Disponible en línea In: http://www.ambitojuridico.com/BancoConocimiento/N/ noti142811-05mas_de_84000_hectareas_se_han_restituido_a victimas_del_co/noti142811-05mas_de_84000_hectareas_se_han restituido_a_victimas_del_co.asp?IDObjetoSE $=21215$

ÁVILA MAHECHA, J.; CRUZ LASSO, Á. Elementos para la discusión de una reforma del IVA en Colombia. DIAN, 2012.

BARREDA, M. La calidad de la democracia en América latina: medición y claves explicativas, 2009. Recuperada de: http://www.aecpa. es/uploads/files/congresos/congreso_09/grupos-trabajo/area04/ GT05/02.pdf

BENSON, A. Revaluando los incentivos tributarios; el ejemplo de la crisis irlandesa. Revista Económica Supuestos. Universidad de los 
Andes, 2011. Disponible In: http://revistasupuestos.uniandes.edu. $\mathrm{co} / \mathrm{p}=2218$

BONILLA, E.; GONZÁLEZ, J. I. La reforma tributaria: soplan vientos de equidad. Razón Pública, Abril 2, 2012. Disponible In: http://www. razonpublica.com/index.php/econom\%C3\%ADa-y-sociedad/2841la-reforma-tributaria-soplan-vientos-de-equidad.html

CARDONA LÓPEZ, A. Gasto público social en Colombia 2000-2010, 2010. Recuperado de: https:/colaboracion.dnp.gov.co/CDT/ Estudios\%20Econmicos/Gasto\%20P\%C3\%BAblico\%20Social\%20 Colombia\%202000-2010.pdf

CEPAL. La hora de la igualdad: brechas por cerrar, caminos por abrir. Trigésimo Tercer Período de Sesiones de la CEPAL, 2010.

COMISIÓN ECONÓMICA PARA AMÉRICA LATINA. Panorama social de América latina, Naciones Unidas-Cepal, 2014. Santiago de Chile. Recuperado de: http://repositorio.cepal.org/bitstream/ handle/handle\%20/11362/S1420729_es.pdf?sequence $=37626$

CORBETTTA, J.; PÉREZ-LIÑÁN, A. Calidad de la democracia: Un análisis de la trayectoria argentina. Instituciones y Desarrollo, 10, 2001, pp. 149-169.

DAHL, R. A. Poliarchy: Participation and Opposition, Yale University Press, New Haven, 1971. . La democracia y sus críticos. Madrid: Paidós, 1992.

DINERO. Colombia es el campeón de la desigualdad en América Latina. Mayo de 2011. Disponible In http://www.dinero.com/economia/ articulo/colombia-campeon-desigualdad-america-latina/120728

DIAMOND, L.; MORLINO, L. The Quality of Democracy. An Overview. Journal of Democracy, Vol. 15, no 4, 2004, pp. 20-31.

DUQUE DAZA, J. El Leviathán derruid. La calidad de la democracia en Colombia, In: TOVAR, J. y PACHANO, S. (Eds.). La calidad de la democracia en América Latina. Quito: Flacso, En imprenta, 2014.

PIZARRO, E.; BEJARANO, A. M. (Eds.). La crisis de representación democrática en los países andinos. Bogotá: Norma, 2007.

EL PAÍS. Primera condena por racismo en Colombia a un concejal de Risaralda. Noviembre 28 de 2014. Recuperado de: http://www.elpais.com.co/elpais/ colombia/noticias/condenan-concejal-marsella-risaralda-por-racismo 
EL TIEMPO. Analfabetismo en niños que viven en el campo alcanzan el 11.5\%. Agosto de 2015. Disponible en: http://m.eltiempo.com/ economia/sectores/analfabetismo-en-ninos-que-viven-en-campocolombiano-alcanza-115-/16219895/1

FUNCIÓN PÚBLICA. Informe sobre la participación femenina en el desempeño de cargos directivos de la administración pública colombiana, 2014. Disponible en: http://portal.dafp.gov.co/form/ formularios.retrive_publicaciones?no $=2411$

GARAY, L. J. et.al. La reconfiguración cooptada del Estado: más allá de la captura económica del Estado, 2008. Disponible en http://www. transparenciacolombia.org.co/Portals/0/ Captura\%20del\%20Estad. pdf

GÓMEZ SABAÍNI, J. C.; ROSSIGNOLO, D. La tributación sobre las altas rentas en América Latina. In: JIMÉNEZ, J. P. Desigualdad, concentración del ingreso y tributación sobre las altas rentas en América latina. Santiago de Chile: Ed. Naciones Unidad-Cepal, 2015, pp.49-116.

HAGOPIAN, F. Derechos, representación y la creciente calidad de la democracia en Brasil y Chile. Politica y Gobierno, Vol. XII, nº1, pp. 41-90, 2005.

ÍNDICE DE DESARROLLO HUMANO AJUSTADO POR DESIGUALDAD, 2014. Disponible en: http://www.undp.org/ content /dam/undp/library/corporate/HDR/ 2014HDR/HDR-2014Spanish.pdf

HELLMAN, J.; KAUFMANN D. La captura del Estado en economías en transición, 2001. Disponible en: https://www.imf.org/external/pubs/ $\mathrm{ft} /$ fandd/spa/2001/09/pdf/hellman.pdf

LICEA DORANTES; S. ¿Calidad de la democracia o calidad del Estado? Un acercamiento a la democracia desde la construcción del Rule of Law. Espacios Públicos, Vol. 14, n. 32, pp.78-102, 2001.

LEVINE, D. H.; MOLINA, J. E. La calidad de la democracia en América Latina: una visión comparada. América Latina Hoy, nº.45, pp.17-46, 2007.

MAINWARING, S. Deficiencias estatales, competencia entre partidos y confianza en la representación democrática en la región andina. In: Scott MAINWARING, S.; BEJARANO, A. M. and PIZARRO E. (Eds.). La crisis de la representación democrática en los países 
andinos. Bogotá: Editorial Norma, 2008. pp.441-515.

MAINWARING, S.; PÉREZ-LIÑÁN, A. Regime Legacies and Democratization: Explaining Variance in the Level of Democracy in Latin America, 1978-2004. Documento de trabajo 354, Kellogg Institute for International Studies, 2008.

MAINWARING, S. Introduction: Democratic Accountability in Latin America. In: MAINWARING, S.; WELNA, C. (Eds.). Democratic Accountability in Latin America. Oxford: University Press Oxford, 2003, pp. 3-33.

MANN, M. The Sources of Social Power. New York: Cambridge University Press, 1986.

MORLINO, L. La calidad de la democracia. Claves de razón práctica, nº193, pp. 26-35, 2009.

. La calidad de las democracias en América Latina. IDEA, 2013.

ROTBERG, R. y CLAPHAM, C. Estados fallidos yo fracasados. Un debate inconcluso y sospechoso. Bogotá: Uniandes, 2005.

O'DONNELL, G. Hacia un Estado de y para la democracia. Democracia/ Estado/Ciudadanía. Hacia un Estado de y para la democracia en América Latina. Lima: PNUD, 2007, pp.25-64.

. Estado y democracia: ¿Cómo avanzar en la construcción institucional que requiere una democracia de ciudadanía? Seminario Internacional Democracia, Estado y Ciudadanía en América Latina. México, 15 de octubre de 2008.

OFICINA DEL ALTO COMISIONADO PARA LA PAZ. ¿Qué se ha acordado en La Habana? 2014. Recuperado de: http://www. altocomisionadoparalapaz.gov.co/herramientas/documentos-ypublicaciones/Documents/Que\%CC\%81_se_ha_acordado_en_La_ Habana.pdf

ONIC: Campaña "Palabra dulce, aire de vida: Forjando caminos para la pervivencia de los pueblos indígenas en riesgo de extinción en Colombia”. ONIC, 2010. Disponible In: www.onic.org.co.

PORTAFOLIO. " $52 \%$ de la tierra en Colombia le pertenece al $1.5 \%$ de población". Septiembre 28 de 2011. Disponible In: http://www. portafolio.co/economia/52-tierra-colombia-le-pertenece-al-15poblacion 
PROGRAMA DE LAS NACIONES UNIDAS PARA EL DESARROLLO. Políticas públicas para el avance dela población afrocolombiana. Revisión y análisis, 2010. Disponible In: http://www. afrodescendientesundp.org/FCKeditor_files/File/PP_AVANCE_ POB_\%20AFROCOLOMBIANA.pdf

REVISTA SEMANA. "Así es Colombia rural”. Informe Especial, 2012. Disponible In: http://www.semana.com/especiales/pilares-tierra/ asi-es-la-colombia-rural.html

STEINER, R.; CAÑAS, A. Tributación y equidad en Colombia, 2013. Disponible en línea In: http://www.repository.fedesarrollo.org. co/bitstream/11445/339/1/Tributaci\%C3\%B3n-y-Equidad-enColombiaSteinerFinal-2.pdf

URREA, F. Diversidad laboral e inclusión en el sector empresarial colombiano. Bogotá: USAD, 2014.

Recebido: 30/08/2015.

Aprovado: 10/11/2015. 